Pure Appl. Geophys. 167 (2010), 933-958

The original publication is available at:

http://www.springerlink.com/content/t66277788xmht483/

\title{
Distribution of seismicity before the larger earthquakes in Italy in the time interval 1994-2004
}

\author{
S. Gentili \\ Istituto Nazionale di Oceanografia e di Geofisica Sperimentale \\ Dipartimento Centro Ricerche Sismologiche \\ Via Treviso 55 - 33100 Cussignacco (Udine), Italy \\ Tel. +39040 2140126, Fax. +390432 522474 E-mail: sgentili@inogs.it
}

Keyword: Region-Time-Length, seismic quiescence, Improved RTL, precursory seismic activity, Italy, earthquake forecasting

Short title for the page headings: Seismicity distribution before Italian earthquakes 


\begin{abstract}
The Region-Time-Length (RTL) algorithm has been applied to different instrumental catalogues to detect seismic quiescence before medium-to-large earthquakes in Italy in the last two decades. RTL performances are sensitive to the choice of spatial and temporal parameters. The method for automatic parameters selection developed by $\mathrm{Chen}$ and $\mathrm{Wu}$ has been applied to 12 Italian earthquakes with magnitude greater than 5. The limits of the method in constructing maps of seismic quiescence before the earthquake are demonstrated, and a simple improvement is proposed. Then a new technique, namely $\mathrm{RTL}_{\text {surv }}$, is proposed for routine surveys of the Italian seismicity. RTL $_{\text {surv }}$ has been applied to all the earthquakes with magnitude greater than 4 in the Italian area in the time interval 1994-2004; 4 different sub-areas have been identified, with different characteristics in the level of recorded seismicity. One sub-area - Tyrrhenian Sea - was characterized by a too low level of recorded seismicity for the application of the method. In the other three sub-areas a seismic quiescence was detected before at least the $66 \%$ of the earthquakes with magnitude greater or equal to 4 and all the earthquakes with magnitude greater than 5 .
\end{abstract}

\title{
1. Introduction
}

Temporal seismic observations have shown trends of seismic quiescences and foreshock activation preceding large events. Many studies focussed on the quiescence occurring during the phase of seismic energy accumulation before moderate and large earthquakes (Scholz 1988, Wyss and Habermann 1988, Wiemer and Wyss 1994), or on the increase of seismicity (Bufe and Varnes, 1993, Brehm and Braile 1998). The RTL analysis is a statistical method developed by Sobolev and Tyupkin $(1996,1997)$ to detect seismic anomalies preceding isolated large earthquakes.

The RTL has been previously applied to large earthquakes in Kamchatka and Caucasus (Sobolev and Tyupkin 1997, 1999, Huang, 2004), Greece (Sobolev et al. 1997), Japan (Huang and Sobolev 2002, Huang et al. 2001, Huang and Nagao 2002, Huang 2004, 2006), Turkey (Huang et 
al. 2002, Huang 2004), Taiwan (Chen and Wu 2006) and China (Jiang et al. 2004, Rong and Li, 2007). Using this technique, earthquakes in Italy have been studied by Di Giovambattista and Tyupkin (1999, 2000, 2004) and by Gentili and Bressan (2007).

In this paper, I present new results for the Italian area, analyzing the medium-to-large earthquakes of two catalogues of instrumental seismicity, the first one compiled at the national scale, and the second one referred to NE Italy (see section 3). A preliminary analysis has been done on $M>5$ earthquakes using the method for the automatic parameters calibration developed by Chen and $\mathrm{Wu}$ (2006). In this paper, I analyze the space of the parameters to show how their choice influences the spatial mapping of RTL before the earthquake. A simple improvement of the Chen and $\mathrm{Wu}$ method is then proposed.

The choice of the time window to perform RTL mapping is one of the most critical points of the method. It is generally done a-posteriori (e.g. Di Giovambattista and Tyupkin, 2000, Huang and Sobolev, 2002), selecting a time window where RTL function for the examined earthquake assumes low values. In this paper, I propose a new method for routine surveys of the Italian seismicity, named $\mathrm{RTL}_{\text {surv }}$; it takes into account the seismicity of the last years before a predefined time, without an ad hoc choice of the time window.

This survey has been applied to all the $M>4$ earthquakes of the national and regional catalogues in the time period 1994-2004. The performance of the method in terms of quiescence detection and spatial location of the anomalies has been evaluated with respect to earthquake magnitudes.

\section{The RTL algorithm and its improved versions}

The RTL algorithm was originally proposed by Sobolev and Tyupkin (1996) and it has been described in detail elsewhere (see e.g. Di Giovambattista and Tyupkin, 2004). Briefly, it represents 
the deviations from the background seismicity. Quiescence is outlined by a decrease of an RTL function, and activation of seismicity by an increase of RTL.

The RTL value at a given test site $(x, y)$ at time $t$, is defined as the product of the epicentral function $R$, the temporal function $T$ and the source-site function $L$, divided by their standard deviations (eq. 1).

$R T L(x, y, t)=\frac{R(x, y, t)}{\sigma_{R}} \cdot \frac{T(x, y, t)}{\sigma_{T}} \cdot \frac{L(x, y, t)}{\sigma_{L}}$

These functions are defined as:

$R(x, y, t)=\sum_{i=1}^{n} \exp \left(-\frac{r_{i}}{r_{0}}\right)-R_{s}(x, y, t)$

where $r_{i}$ is the distance between the test site $(x, y)$ and the $i^{\text {th }}$ earthquake, $2 r_{0}$ is the search distance and the summation is performed on the $n$ events considered in the time window $\left(t-2 t_{0}, t\right)$, having magnitude in the interval $\left(M_{\min }, M_{\max }\right)$, with $M_{\min }=M_{c}$, the level of the catalogue completeness.

In the temporal term

$$
T(x, y, t)=\sum_{i=1}^{n} \exp \left(-\frac{t-t_{i}}{t_{0}}\right)-T_{s}(x, y, t)
$$

$t_{i}$ is the time of occurrence of the events preceding the time of the forecast. Finally, the source-site function is

$$
L(x, y, t)=\left\{\begin{array}{llc}
\sum_{i=1}^{n}\left(\frac{l_{i}}{r_{i}}\right)-L_{s}(x, y, t) & \text { if } & r_{i}>\varepsilon \\
\sum_{i=1}^{n}\left(\frac{l_{i}}{\varepsilon}\right)-L_{s}(x, y, t) & \text { if } & r_{i} \leq \varepsilon
\end{array}\right.
$$

where $\varepsilon$ is the accuracy of the epicenter location and $l_{i}$ is the size of the source of the selected earthquakes; $l_{i}$ is usually calculated from empirical relationships between earthquake magnitude and source size. $R_{s}, T_{s}$, and $L_{s}$ are linear trend corrections.

The RTL function is calculated after declustering the earthquake data set. 
Various improvements of the method or different interpretations of the results have been proposed. In Jiang et al. (2004) and Chen and Wu (2006), both decreases and increases of RTL are considered earthquake precursors, while for most other authors (see e.g. Huang and Sobolev 2002) only a decrease (seismic quiescence) is considered a reliable precursor.

One of the open problems in the application of the method is the choice of the free parameters $r_{0}, t_{0}$ and $M_{\max }$. Huang (2006) on the large Tottori earthquake (M=7.3) and Gentili and Bressan (2007) on a set of moderate earthquakes in NE Italy and Western Slovenia, show that the results are stable for a large range of chosen parameters. Chen and $\mathrm{Wu}$ (2006) propose a method for the choice of the most stable value of $r_{0}$ and $t_{0}$, described in detail in the following. In some recent papers, no $\mathrm{M}_{\max }$ is imposed, to avoid the introduction of potential artificial changes by the two cutoff magnitudes $M_{\min }$ and $M_{\max }$ (Huang and Sobolev, 2002, Huang 2004, 2006, Chen and Wu, 2006), or because the $M_{\max }$ is demonstrated to not influence the results (Gentili and Bressan, 2007). In previous papers $M_{\text {max }} \approx M_{\text {seq }}-2$, where $M_{\text {seq }}$ is the magnitude of the tested main shock (Sobolev and Tyupkin 1997), or it is set to a given value, like Di Giovambattista and Tyupkin (1999, 2000, 2004), who set $M_{\max }=3.8$ independently of the magnitude of the tested mainshock. In this paper, I exclude $\mathrm{M}_{\max }$ from the RTL calculation.

Another open problem is how to map RTL in space, in order to detect the seismic quiescence zone. The region in the neighborhood of the epicenter (its dimension changes from author to author, ranging from $150 \times 250 \mathrm{~km}$ in $\mathrm{Di}$ Giovambattista and Tyupkin (2004) to 1900x1800 km in Huang et al. (2001)), is sampled by a grid, and, for every node of the grid, the RTL is computed for the same time window containing the minimum value of the RTL at the epicenter of the analyzed earthquake. The value mapped is in some cases the minimum of the RTL in the time window $\left(\mathrm{RTL}_{\min }\right.$ - see e.g. Sobolev 2000, Di Giovambattista and Tyupkin 2000 and 2004). In most recent papers, the Q parameter is mapped, which is defined as the mean of the RTL in the considered time window (Huang et al. 2002, Huang 2004, 2006). In both cases, this analysis must be done a-posteriori, when the position of the epicenter of the earthquake is known. This is a 
drawback, since it lowers the interest of RTL as earthquake predictor. Section 4.3 describes the method proposed in this paper to solve this problem.

\section{Data-set pre-processing}

Two earthquake catalogues have been used in this paper, pertaining to the regional and national scale. The first one is the regional catalogue released by the Seismic Network of Northeastern Italy, managed by the Seismological Research Center (CRS) of OGS - National Institute of Oceanography and Experimental Geophysics. The catalogue (hereinafter defined as NEI catalogue) reports 16200 events with $\mathrm{M}>0$ from May 1977 (Fig. 1a). A full description of the characteristics of the monitoring is reported in Priolo et al. (2005), and the list of events located using HYPO71 (Lee and Lahr, 1975) is public and available on the web site http://www.crs.inogs.it/bollettino/RSFVG/RSFVG.en.html. The magnitude adopted in this catalogue is the duration magnitude obtained using the Rebez and Renner (1991) formula. The mean location uncertainty is $1.5 \mathrm{~km}$.

\section{$<$ Figure 1 here $>$}

The second catalogue covers the whole country, and it is the one proposed by Lolli and Gasperini (2006) (L\&G catalogue). It is a compilation obtained by integrating with uniform criteria different catalogues, namely the PFG catalogue (Postpischl, 1985) that reports macroseismic and instrumentally derived records from 1000 to 1980, the CSTI catalogue (CSTI WorkingGroup, 2001, 2004; instrumental seismicity from 1981 to 1996), the CSI catalogue (Castello et al., 2005; earthquakes in 1981-2002) and two years (2003-04) of instrumental bulletins of the Istituto Nazionale di Geofisica e Vulcanologia (INGV) available at site http://legacy.ingv.it/ roma/reti/rms/bollettino. The resulting catalogue (Fig. 1b) reports 64200 events with M>0 from January 1960 to December 2004 and can be downloaded by anonymous ftp at the address: ibogfs.df.unibo.it and it is in the directory LOLLI/AFT2005 (Lolli and Gasperini, 
2006). The magnitude listed is local magnitude. The mean location uncertainty is $7.5 \mathrm{~km}$ (Lolli and Gasperini 2003).

\subsection{Declustering}

RTL applies to declustered catalogues, where both foreshocks and aftershocks are removed. In order to decluster the L\&G and NEI catalogues, I have applied and compared the performances of two alternative algorithms: that by Knopoff et al. (2000) and that by Reasenberg (1985), the latter implemented in Zmap software (Wiemer, 2001). The whole Zmap software package can be downloaded from the Swiss Federal Institute of Technology Zurich (ETH Zurich) web pages (http://www.earthquake.ethz.ch/software/).

Knopoff algorithm, for $\mathrm{M}_{\mathrm{L}}<6.4$, is a windowing algorithm for cluster identification. It means that for every event in the catalogue a space time-window is defined and any earthquake within the window is deemed as cluster event. The extension in time and in space of the window depends on the magnitude of the earthquake. In applying the algorithm to L\&G catalogue, I used of the original table proposed by Knopoff et al. (2000), extended to smaller magnitudes as in Pace et al. (2006) in Italian catalogues declustering:

$$
\begin{aligned}
& \log (T)=0.725 M_{L}-2.007 \\
& \log (D)=0.347 M_{L}-0.567
\end{aligned}
$$

where $T$ and $D$ are the time and space windows expressed in days and kilometers, respectively, and $M_{L}$ is the local magnitude. For NEI catalogue declustering, since the listed magnitude is the duration magnitude, I adopted the relationships obtained by Gentili and Bressan (2008) for the area covered by the catalogue:

$$
\begin{aligned}
& \log (T)=0.33 M_{D}+0.42 \\
& \log (D)=0.41 M_{D}-1
\end{aligned}
$$


where $M_{D}$ is the duration magnitude. For simplicity, since the algorithm is the same for NEI and L\&G catalogues, even if the relations (5) and (6) are different, this algorithm will be referred in the following simply as modified Knopoff algorithm.

The Reasenberg algorithm defines a seismic sequence as a chain of events linked each other by spatial and temporal windows. The window's extension in time and space depends on a set of parameters and on the seismic moment of the largest and the most recent event. In particular, the spatial extent of the mainshock is taken coincident with its source dimension; that is (Kanamori and Anderson 1975):

$$
r=\left(\frac{7}{16} \frac{M_{0}}{\Delta \sigma}\right)^{1 / 3}
$$

where $\Delta \sigma$ is the stress drop, assumed $3 \mathrm{MPa}$ for all the earthquakes, and $\mathrm{M}_{0}$ is the seismic moment. The spatial extent of the most recent event is its source dimension scaled by a parameter Q. A location uncertainty is considered in the calculation. The temporal window is defined as a function of the time $t$ after the beginning of the sequence:

$$
\tau=\frac{-\ln (1-P) t}{10^{K}}
$$

where $P$ is related to the probability of observing one or more events and $K$ is related to the mainshock magnitude. An upper and lower limit for $\tau\left(\tau_{\min }\right.$ and $\tau_{\max }$, respectively) are input parameters. Since the characteristics of the catalogues and of the seismicity in California, for which the algorithm was developed, are different, I tested the declustering using both the default parameters $\left(\mathrm{Q}=10, \tau_{\min }=1, \tau_{\max }=10, \mathrm{P}=0.95\right)$ and the ones proposed for Italy by Lolli and Gasperini (2003) $\left(\mathrm{Q}=20, \tau_{\min }=2, \tau_{\max }=10, \mathrm{P}=0.99\right)$. Lolli and Gasperini (2003) double the spatial extent of the window.

I used the following conversion rule between local magnitude and seismic moment (Lolli and Gasperini 2003, Gasperini and Ferrari 2000):

$$
\log _{10}\left(M_{0}\right)=1.22 M_{L}+17.7
$$


In order to find a relation between duration magnitude and seismic moment valid for Northeastern Italy, I used the data of moment magnitude listed in Franceschina et al. (2006) and Bressan et al. (2007) obtaining the following regression (see Fig 2):

$$
\begin{aligned}
& \log _{10}\left(M_{0}\right)=1.3 M_{D}+9.3 \\
& \sigma\left(\log _{10}\left(M_{0}\right)\right)=0.3
\end{aligned}
$$

where $\sigma($.$) is the standard deviation.$

\section{$<$ Figure 2 here $>$}

In Fig. 1a and $\mathrm{b}$ the cumulative number of earthquakes with magnitude $>0$ for the two catalogues are compared with their declustered version after applying (i) the declustering obtained by applying Knopoff et al. (2000) algorithm (ii) the Reasenberg algorithm with default parameters (iii) the Reasenberg algorithm with Lolli and Gasperini parameters.

The NEI catalogue (Fig. 1a) presents a clear increase on the number of earthquakes corresponding to the seismic sequences of the $12^{\text {th }}$ April $1998 \mathrm{M}_{\mathrm{D}}=5.6$ and the $12^{\text {th }}$ July 2004 $\mathrm{M}_{\mathrm{D}}=5.1$ Kobarid earthquakes. A smaller increase of the cumulative number of earthquakes can be seen also due to the seismic sequence of the $1^{\text {st }}$ February $1988 \mathrm{M}_{\mathrm{D}}=4.1$ Mena earthquake (for more details on the sequences in this area, see Gentili and Bressan 2008). All the declustering procedures were able to eliminate these increases. In addition, in both the original and declustered catalogue it is possible to see a decrease in slope of the curve in 1988. This is due to the change of the data acquisition method. The seismic data acquisition before January 1, 1988 was analog, all the data were collected and there was no triggering algorithm. After this date, the seismicity was acquired with digital signal processing; the signal was acquired when the ratio (Short Term Average)/(Long Term Average) passed a given threshold. Therefore, smaller magnitude earthquakes were neglected (Marcellini and Milani 2003). The seismicity recording was interrupted on December 3, 1990 and started again on May 21, 1991 (Gentili and Bressan 2007). The interruption is marked by two dashed lines. The main difference in the results of the declustering procedures is in the number of events in the declustered catalogues. While modified Knopoff algorithm removes about 2800 events 
out of the 16200 with $M_{D}>0$ from the catalogue, Reasenberg algorithm removes 4800 and 5800 events using default and Lolli and Gasperini parameters, respectively. In order to understand which is the best declustering procedure, I verified their performances on two seismic sequences and a swarm, whose events are listed in Bressan et al. (2007). I found that the best procedure is the Knopoff (2000) algorithm. The mainshocks of the sequences are the $12^{\text {th }}$ April $1998 \mathrm{M}_{\mathrm{D}}=5.6$, Kobarid and the $14^{\text {th }}$ February $2002 \mathrm{M}_{\mathrm{D}}=4.9$ Sernio Mountain earthquakes. The swarm was composed of three sequences whose mainshocks were the $27^{\text {th }}$ January $1996 \mathrm{M}_{\mathrm{D}}=3.5$, the $27^{\text {th }}$ February $1996 \mathrm{M}_{\mathrm{D}}=3.8$ and the $13^{\text {th }}$ April $1996 \mathrm{M}_{\mathrm{D}}=4.3$ Claut earthquakes. The results are the following:

- Knopoff (2000) algorithm correctly removes from the catalogue all the dependent earthquakes of the seismic sequences; all the mainshocks are correctly recognized.

- Reasenberg algorithm using default parameters fails in removing two aftershocks in Sernio sequence and one in the last sequence of the Claut swarm. In addition, it wrongly removes the $13^{\text {th }}$ April $1996 \mathrm{M}_{\mathrm{D}}=4.3$ Claut mainshock from the catalogue.

- Reasenberg algorithm using Lolli and Gasperini parameters fails in removing two aftershocks in Sernio sequence. In addition, it wrongly removes the $13^{\text {th }}$ April $1996 \mathrm{M}_{\mathrm{D}}=4.3$ Claut mainshock from the catalogue.

The same analysis was performed on the $L \& G$ catalogue (see fig $1 b$ ). The $L \& G$ catalogue presents a remarkable increase of the number of earthquakes due to the cluster of earthquakes in Umbria-Marche started on $26^{\text {th }}$ September 1997. Minor increases can be seen corresponding to the seismic sequence of the $6^{\text {th }}$ May $1976 \mathrm{M}_{\mathrm{L}}=6.1$ Friuli earthquake, of the $29^{\text {th }}$ April $1984 \mathrm{M}_{\mathrm{L}}=5.2$ Gubbio/Valfabbrica earthquake and of the $6^{\text {th }}$ September and $31^{\text {st }}$ October $2002 \mathrm{M}_{\mathrm{L}}=5.6$ Palermo and $\mathrm{M}_{\mathrm{L}}=5.6$ Molise earthquakes. All the declustering procedures were able to eliminate these increases. A change of slope of the cumulative number of earthquakes can be seen around the year 1995 in both the original and the declustered catalogues. This is due to a change in the network acquisition system in 1994 (Lolli and Gasperini 2003) and an increase of the number of seismic 
stations in 1996 that improved the detection capability of some Italian regions (e.g. in Sicily: see Di Giovambattista and Tyupkin, 2004). In this case also, the main difference among the declustered catalogues is the number of earthquakes. While the modified Knopoff algorithm removes about 13400 events out of the 64200 with $M_{L}>0$ from the catalogue, Reasenberg algorithm removes 19200 and 26300 events using default and Lolli and Gasperini parameters, respectively. In order to make a comparison between declustering the methods, I verified their performances on UmbriaMarche seismicity in 1997 using the data from Selvaggi et al. (2002) in order to have a more accurate location of the earthquakes ipocenters; the dataset was composed of 646 earthquakes. The modified Knopoff algorithm detects 15 independent events, recognizing all the distinct ruptures of fault segments, while Reasenberg algorithm recognized 8 and 4 independent events using default and Lolli and Gasperini parameters, respectively. These results and the final choice of modified Knopoff algorithm are in agreement with the ones obtained by Pace et al. (2006) on the same data.

\subsection{Completeness}

The magnitude of completeness has been evaluated for the two catalogues by using the Entire Magnitude Range method (EMR) (Woessner and Wiemer 2005) and a bootstrapping method for uncertainties evaluation. The software adopted was Zmap. The analysis was performed on declustered catalogues, since during large clusters or aftershock sequences a different policy of recording with respect to standard background seismicity is generally applied (see also Schorlemmer and Woessner 2008). The magnitude of completeness for NEI catalogue is $\mathrm{M}_{\mathrm{D}}=1.9 \pm 0.4$ using modified Knopoff 2000 declustering method, $2.3 \pm 0.07$ and $2.3 \pm 0.05$ using Reasenberg method with standard and Lolli and Gasperini parameters, respectively. The magnitude of completeness for $L \& G$ catalogue is $M_{L}=2.1 \pm 0.09$ using modified Knopoff 2000 declustering

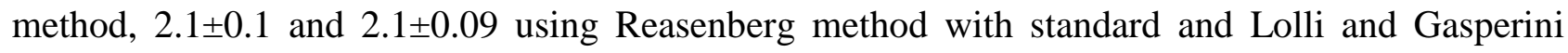
parameters, respectively. 
However, the study of the whole catalogue hides the changes in time and space of $\mathrm{M}_{\mathrm{c}}$, depending on the seismic network available. Fig. 3 shows the changes in time of $\mathrm{M}_{\mathrm{c}}$ for both catalogues, calculated using Zmap software. It is possible to notice an increase of $\mathrm{M}_{\mathrm{c}}$ for NEI catalogue in the time interval 1985-1990 and a successive stabilization on larger values, due to the change in network acquisition system (see also section 3.1). The L\&G catalogue is characterized by a general decrease of the completeness magnitude from 1986 to the end of 2002. An increase of $\mathrm{M}_{\mathrm{c}}$ is clearly detectable in 2003, when the instrumental bulletin data were merged with pre-existing catalogues.

\section{$<$ Figure 3 here>}

In order to manage homogeneous catalogues, both in terms of network structure and of acquisition system, without interruptions in data recording, in a mostly overlapping time period, the analysis is performed for NEI catalogue from $21^{\text {st }}$ May 1991 until the end of 2004 and for L\&G catalogue from $1^{\text {st }}$ January 1986 until the end of 2004.

\subsection{Selection of target events}

The RTL analysis needs a seismicity recording time interval, before the target event, in order to become stable. The duration of this time interval depends on the earthquake rate in the region under study and on the completeness magnitude of the catalogue. For studies in Italy, this time interval ranges between 6 years for the $1996 \mathrm{M}_{\mathrm{D}}=4.3$ Claut earthquake (Gentili and Bressan 2007) to 12 years for the $2002 \mathrm{M}_{\mathrm{L}}=5.6$ earthquake (Di Giovambattista and Tyupkin, 2004). Table 1 shows all the earthquakes in Italy and in the surrounding regions with M>5, from $1^{\text {st }}$ January 1994 to $31^{\text {st }}$ December 2004, listed in NEI and L\&G catalogue; the $14^{\text {th }}$ February $2002 M_{D}=4.9$ earthquake is analyzed as a $M_{L}>5$ earthquake, even if $L \& G$ catalogue lists it as $M_{L}=4.9$, because its local magnitude is considered in this paper to be $\mathrm{M}_{\mathrm{L}}=5.1$ in accord with Franceschina et al. (2006). 
All the earthquakes analyzed are preceded by a time interval of at least 7 years of available data in the catalogue adopted for RTL analysis (see later).

In order to apply the RTL method for retrospective earthquake forecasting with reliable results, the following selection rules have been applied:

1. In cases of swarms or seismic sequences only the first shock with magnitude greater than 5 is considered.

2. Deeper earthquakes (deeper than $200 \mathrm{~km}$ earthquakes) are not analyzed.

The first choice is made because RTL has been developed for detecting seismic anomalies preceding isolated large earthquakes. A quiescence preceding a large earthquake precedes also its seismic sequence or the other earthquakes composing a seismic swarm. RTL does not allow a discrimination between one or more shocks following a seismic quiescence. According to point 1, six Umbria-Marche earthquakes and the $1^{\text {st }}$ November 2002 Molise earthquake (in italic in Table 1) are rejected from the target events list. The second choice is done to avoid confusion between shallower seismicity quiescence and deeper events; this choice causes the rejection of other 3 earthquakes from the target events list: the $M_{L}=5.75^{\text {th }}$ January 1994 and the $M_{L}=5.418^{\text {th }}$ May 1998 South Tyrrhenian Sea earthquakes and the $\mathrm{M}_{\mathrm{L}}=5.35^{\text {th }}$ May 2004 Aeolian Islands earthquake. The 12 earthquakes analyzed are listed in boldface in Table 1. In order to avoid artifacts due to the mixing of the two different kinds of magnitude listed in NEI and L\&G catalogues, which can cause fake quiescence patterns (see also Habermann 1987 and Wyss 1991), the analysis for each earthquake is done using only the catalogue that better covers the epicentral area. In particular, Sernio Mountain and the two Kobarid earthquakes are analyzed by using NEI catalogue, while for the other 9 earthquakes $L \& G$ catalogue is adopted. 


\section{RTL analyses}

In order to analyze the parameter dependence of RTL, the algorithm has been retrospectively tested on $\mathrm{M}>5$ earthquakes, using both the Chen and $\mathrm{Wu}$ (2006) method and standard values. The comparison has been performed also with results in the literature, when available. The parameters' choice affects both the duration of the detected seismic quiescence and the spatial extension of quiescence area. A simple improvement of the Chen and $\mathrm{Wu}(2006)$ method, that reduces the spatial extension of quiescence area, is proposed. In addition, a survey method for the whole Italian area, based on RTL, is presented.

\subsection{Retrospective forecasting of $M>5$ earthquakes}

The RTL has been calculated at the epicenter of the 12 earthquakes listed in bold in Table1. When L\&G was the reference catalogue, the relation adopted by Di Giovambattista and Tyupkin (1999) (Papadopoulus and Voidomatis, 1987) for $l_{i}$ evaluation has been taken:

$\log _{10}(l)=0.44 M_{L}-1.289$

where $l$ is the size in $\mathrm{km}$ of the seismic source and $M_{L}$ is the local magnitude. The accuracy of the epicenter location was given as $\varepsilon=7.5 \mathrm{~km}$ (Lolli and Gasperini 2003). The analysis started on $1^{\text {st }}$ January 1986 and lasted until midnight of the day before the considered mainshock.

If the NEI catalogue was used, an additional conversion rule was invoked before applying equation (11):

$\mathrm{M}_{\mathrm{L}}=1.2 \mathrm{M}_{\mathrm{D}^{-}}-0.73$

where $M_{L}$ is the local magnitude and $M_{D}$ is the duration magnitude (Gentili and Bressan 2008). The accuracy of the epicenter location adopted was the mean of value of horizontal errors given by the location procedure (HYPO71) given as $\varepsilon=1.5 \mathrm{~km}$. The time interval considered was from $21^{\text {st }}$ May 1991 to midnight of the day before the considered mainshock. 
In order to avoid artifacts due to heterogeneities in the completeness threshold in the catalogues in different regions of Italy, $\mathrm{M}_{\mathrm{c}}$ has been evaluated for each earthquake, by the EMR method implemented in Zmap software, using a search radius of $100 \mathrm{~km}$ from the epicenter, by analyzing also its variation in time, from the "starting date of the catalogue" ( $1^{\text {st }}$ January 1986 for the L\&G catalogue, $21^{\text {st }}$ May 1991 for NEI) until the date of the studied events. The highest value reached by $M_{c}$ has been set as minimum magnitude for computation. The $\mathrm{M}_{\mathrm{c}}$ adopted for each earthquake is listed in Table 2.

The $t_{0}$ and $r_{0}$ parameters have been estimated using the search method developed by Chen and $\mathrm{Wu}(2006)$ :

- The $t_{0}$ parameter was varied in the range $\left[\mathrm{t}_{0 \min }, \mathrm{t}_{0 \max }\right]$ with step $\Delta \mathrm{t}_{0}$.

- For each value $\hat{t}_{0}$ of $t_{0}$, a set of $\operatorname{RTL}\left(\hat{t}_{0}, \mathrm{r}_{0}\right)$ was calculated, varying the value of $\mathrm{r}_{0}$ in the range $\left[\mathrm{r}_{0 \min }, \mathrm{r}_{0 \max }\right]$ with step $\Delta \mathrm{r}_{0}$.

- The RTLs were considered two by two and their correlation coefficients at a significance level of 0.05 (Bendat and Piersol, 2000) were evaluated.

- The percentage $p\left(\hat{t}_{0}\right)$ of correlation coefficients over a given threshold $\theta$ was evaluated.

- The value of $t_{0}$ corresponding to the peak value of the distribution of $p\left(t_{0}\right)$ was selected as the best one.

- An analogous approach has been applied to $r_{0}$ parameter.

The method finds the values of the parameters for which the RTL is more stable, eliminating or reducing anomalies correlated with the choice of parameters (Chen and $\mathrm{Wu} 2006)$.

The tested time $t_{0}$ has been varied in this paper from 0.2 to 2 years with steps of 0.1 year; the tested radii from 15 to $80 \mathrm{~km}$ with steps of $5 \mathrm{~km}$. Accordingly with Chen and $\mathrm{Wu}$ (2006), the threshold $\theta$ has been set equal to 0.8 for $t_{0}$ estimation and equal to 0.5 for $r_{0}$ estimation. Different thresholds have been used because changes in $t_{0}$ influence the RTL more than changes in $r_{0}$ (see also Huang, 2004, 2006 and Gentili and Bressan, 2007). The results are summarized in Table 3. The 
values of $t_{0}$ range from 0.4 to 1.4 years, while $r_{0}$ ranges from 15 to $65 \mathrm{~km}$. For most sequences the estimated coefficient $t_{0}$ has more than the $50 \%$ of correlation coefficients greater than 0.8 and the estimated $r_{0}$ has more than $65 \%$ of the correlation coefficients greater than 0.5 .

\section{$<$ Figure 4 here $>$}

In Fig. 4 the obtained RTL is shown by a solid thick line. The RTL obtained with fixed parameters $\left(r_{0}=30 \mathrm{~km}, t_{0}=0.5\right.$ years, used by Di Giovambattista and Tyupkin (2004) for Palermo earthquake) given in literature is plotted too (thin grey line in Fig. 4). It is possible to see that the results in Fig. 4 for different choices of the parameters are generally qualitatively similar, even if the duration of quiescence and the minimum value reached by RTL may change. Three other tests have been done in order to verify the stability of the method.

The first test is done by changing the magnitude threshold used for calculation; the test is repeated for both magnitudes greater than the completeness magnitude and for smaller magnitudes, under the hypothesis that the completeness magnitude is overestimated. In Table 4 the maximum and the minimum magnitude threshold for which the quiescence is detectable are listed, together with the completeness magnitude. Tests on the Reggio Emilia earthquake are not done, because no seismic quiescence is detected. For most earthquakes, the minimum magnitude is 0 (with no magnitude threshold). The only case in which it is larger than 0 is Merano earthquake; however, also in that case, the minimum magnitude is well below the completeness magnitude. The maximum magnitude coincides in all cases with the maximum magnitude for which the number of earthquakes used to calculate RTL is not too small to supply reliable results. I have considered the RTL to be reliable if at least 50 earthquakes are used for calculation. The previous test outlines a good stability of the RTL also for different choices of completeness magnitude.

The second test is done to verify the performances of RTL using the L\&G catalogue in the $\mathrm{NE}$ area. The three $\mathrm{M}>5$ earthquakes in the area, analyzed by NEI catalogue, present a well defined seismic quiescence some years before (Kobarid 1998, Fig. 4d) or immediately before the mainshock (Sernio Mountain and Kobarid 2004 - Fig. $4 \mathrm{~g}$ and $4 \mathrm{~m}$ ) that is stable under a wide interval of 
magnitudes (see Table 4) but also $\mathrm{t}_{0}$ and $\mathrm{r}_{0}$ values (see Table 3 and section 4.2). The same earthquakes are analyzed by applying Chen and $\mathrm{Wu}$ procedure for the choice of $\mathrm{r}_{0}$ and $\mathrm{t}_{0}$ parameters but using the L\&G catalogue. The results are shown in Fig. 5. Comparing figures $4 \mathrm{~d}, 4 \mathrm{~g}$ and $4 \mathrm{~m}$ with the corresponding figures $5 \mathrm{a}, \mathrm{b}, \mathrm{c}$ it is possible to see that the RTL applied to the L\&G catalogue is not able to detect seismic quiescence in Sernio Mountain case (Fig. 5b); it detects a seismic sequence in Kobarid 1998 case but very far from the time of the mainshock (Fig. 5a); only in Kobarid 2004 case (Fig. 5c) are the results qualitatively similar. This is probably due to inaccuracy of earthquake location and magnitude determination of national catalogues in NE area, which is not well covered by the national network (a map of the national seismic network can be found in the Centro Nazionale Terremoti of the Istituto Nazionale di Geofisica e Vulcanologia INGV web pages http://www.cnt.ingv.it).

\section{$<$ Figure 5 here $>$}

The last test on RTL stability is done changing the declustering method. In particular, the declustering is performed by using the Reasenberg declustering method with the parameters of Lolli and Gasperini and the same $r_{0}$ and $t_{0}$ parameters of Fig. 4. The corresponding RTL are shown in the Fig. 6. Using Reasenberg declustering method, the RTL are qualitatively similar to the ones obtained by modified Knopoff method for the most of analyzed earthquakes, with only the exception of the 1998 Calabrian-Lucanian earthquake (Fig 4e and 6e), for which the quiescence preceding the earthquake is less relevant than using Knopoff method (RTL values in the range [0.7,0]), and 2003 Adriatic sea earthquake (Fig 41 and 61), where the RTL could be evaluated only for $r_{0} \geq 30$ due small number of earthquakes after the declustering.

\section{$<$ Figure 6 here>}

Table 5 summarizes the results, in terms of quiescence and successive activation stage duration (when an activation occurred), and of time shift before the analyzed shock, for the RTL calculated using the Knopoff declustering method and the parameters listed in Table 3. If more than one quiescence or activation phase occurred, the last one is considered. Only 3 of the earthquakes 
considered present an activation phase after the quiescence. However, 11 of the 12 analyzed earthquakes present a seismic quiescence. The duration of the quiescence ranges from 0.6 years to 3.0 years. The interval between the start of the quiescence to the earthquake is of the order of years, ranging from 0.6 to 4.0 years. This confirms the results already discussed in Sobolev and Tyupkin (1996) and Huang and Sobolev (2002) for which RTL should be considered an intermediate term precursor (range of years) and is not useful as short term precursor (months to weeks range).

Six of the analyzed earthquakes (Reggio Emilia, Umbria Marche, Kobarid 1998, Sernio Mountain, Palermo, Kobarid 2004) have been already studied using RTL with empirical choices of the parameters (Di Giovambattista and Tyupkin, 1999, 2000, 2004, Gentili and Bressan, 2007). Since the parameters here are generally different from the ones adopted in the literature, the catalogues used for the whole of Italy are different (in particular in Lolli and Gasperini catalogue the magnitude is revised) and the declustering method is different, the comparison can be only qualitative.

RTL does not present any quiescence before the Reggio Emilia earthquake neither in this paper (see Fig. 4b) nor in Di Giovambattista and Tyupkin (1999). An activation stage from the last months of 1995 until the earthquake day $\left(15^{\text {th }}\right.$ October 1986) can be seen in Di Giovambattista and Tyupkin (1999), but not in this paper. The RTL curves before Umbria-Marche (Fig. 4c) and the Palermo (Fig. 4h) earthquakes are qualitatively similar to the ones in the literature (Di Giovambattista and Tyupkin 2000 and 2004, respectively), with an RTL decrease followed by a recovery stage before the main shock. Regarding earthquakes analyzed by the NEI catalogue, (Kobarid 1998, Sernio Mountain and Kobarid 2004 - Fig 4d, g, m respectively) the resulting RTL curves are qualitatively similar to the results presented in the literature (Gentili and Bressan 2007), with a quiescence followed by an activation of seismicity preceding the mainshock in the Kobarid 1998 case (Fig. 4d), and a decrease of RTL until the midnight before the mainshock for the Sernio and Kobarid 2004 earthquakes (Fig. $4 \mathrm{~g}$ and $\mathrm{m}$ ). 


\subsection{Spatial distribution of RTL}

The quiescence region has been mapped in this paper by the Q parameter (Huang et al. 2002) i.e. the mean of the value of RTL in a selected time window. In order to avoid noisy results, only values of $\mathrm{Q} \leq-0.5$ are considered. The time window chosen for each analysis is listed in Table 6. The completeness magnitude is evaluated for the whole area shown in the map by the EMR method by analyzing also the variation in time. The highest value reached has been used for computation and is listed in the table (column 2). Note that $\mathbf{M}_{\mathrm{c}}$ presented in Table 6 is generally larger than the one listed in Table 2, due to the larger area considered in the computation. A first test has been done by using the values selected in the previous section (see Table 3) for the evaluation of RTL at the epicenter of the mainshocks; the radius $r_{0}$ adopted (column 4) is compared with the linear dimension of the quiescence zone (column 5). It is easy to see how the area covered by the quiescence is generally larger for larger values of the radius $r_{0}$, independently of the earthquake analyzed, while the time $\mathrm{t}_{0}$ is not influential. This is not surprising, since enlarging the radius of the RTL causes each point to be affected by the influence of a larger area causing a blurring of the map image. In some cases (see e.g. the Merano earthquake) the area characterized by seismic sequence is so large that RTL loses utility for seismic risk assessment. For this reason, the obvious question is whether it is necessary to use such large radii like e.g. for the Merano earthquake, or if with smaller ones it is possible to obtain reliable results.

In this paper I propose two possible approaches to the problem. The first approach consists simply in setting a threshold $T$ on $r_{0}$, and considering the $\mathrm{r}_{0}$ corresponding to the peak value of $p\left(r_{0}\right)$, for $r_{0} \leq T$, as the best parameter for RTL mapping. I set the threshold to $r_{0}=30 \mathrm{~km}$, that is the value adopted by Di Giovambattista and Tyupkin (2004) for Palermo earthquake; $30 \mathrm{~km}$ is also the minimum radius for which RTL supplies stable results for low seismicity areas like e.g. the Merano earthquake area. The results are listed in column 6 and 7 of Table 6 . It is possible to see that the quiescence is still detectable for the same 11 earthquakes for which it was found using the Chen and 
$\mathrm{Wu}$ method, but in 5 cases the quiescence area extent is smaller. It is particularly interesting in the Merano earthquake case, where the linear dimensions of the quiescence area passes from $800 \mathrm{~km}$ to $200 \mathrm{~km}$.

The second approach merges the stability requirements addressed by the Chen and $\mathrm{Wu}$ method and the additional requirement that $r_{0}$ is as small as possible, in order to reduce the dimension of the quiescence area. The algorithm adopted in this case is the following:

1. The RTL is calculated at the epicenter of the future earthquake, using $r_{0}$ and $t_{0}$ parameters obtained by Chen and $\mathrm{Wu}$ method

2. If a quiescence is detected the analysis time interval is selected (that is one listed in column 3 of Table 6)

3. The $r_{0}$ parameter is recursively reduced, maintaining $t_{0}$ unchanged, evaluating again the RTL

4. The minimum value of $r_{0}$ for which the quiescence is still detectable is selected as the correct parameter for mapping.

This simple method allows study of a quiescence that is stable on a wide range of parameters and on the other side it allows to have smaller quiescence areas. The results are listed in Table 6 (columns 8 and 9) and the corresponding maps are presented in Fig. 7. The linear dimensions of the quiescence regions are smaller than the ones obtained by Chen and $\mathrm{Wu}$ method in $91 \%$ of the cases and range from $50 \mathrm{~km}$ to $450 \mathrm{~km}$.

\section{$<$ Figure 7 here $>$}

All the earthquakes except Reggio Emilia are inside the quiescence zone even if only a few of them coincide with the minimum of $\mathrm{Q}$ while in three cases (Umbria Marche -Fig. 7c, Merano - Fig. 7f, Palermo - Fig. 7h) the earthquake epicenters are close to the borders of the quiescence region. This result is coherent with other results in literature (Huang et al. 2001, 2002, Sobolev 2000).

Of the 12 earthquakes with magnitude > 5 in Italy only for the Umbria Marche and Palermo earthquakes is the RTL map supplied in literature (Di Giovambattista and Tyupkin 2000 and 2004, 
respectively). For Umbria Marche the time interval for the analysis adopted by Di Giovambattista and Tyupkin is different; they chose the time interval $5^{\text {th }}$ September $1996-5^{\text {th }}$ September 1997 , that has no overlap with the time period chosen in this paper $\left(2^{\text {nd }}\right.$ July $1995-1^{\text {st }}$ July 1996). The reason for different choice can be ascribed to the fact that the detected minimum in RTL (seismic quiescence) changes its duration and shape depending on the parameters (see Fig. 4c). The area characterized by the quiescence ranges in Di Giovambattista and Tyupkin paper from approximately $42^{\circ}$ to $44^{\circ}$ in latitude and in longitude from less than $11^{\circ}$ to $14.5^{\circ}$ and covers Italy from one coast to the other. The earthquake epicenter is approximately at the center of the area. The mapping method they adopted is $\mathrm{RTL}_{\text {min. }}$ In this work the $\mathrm{Q}$ method is adopted and a large quiescence area is evident at lower latitude, with the earthquake epicenter on the northern border of the quiescence area. The latitude range is approximately $\left[41^{\circ}-43^{\circ}\right]$ after choosing an $r_{0}$ equal to of $35 \mathrm{~km}$ or $30 \mathrm{~km}$ (see Fig. 8a and b, respectively) and $\left[42^{\circ}-43^{\circ}\right]$ choosing an $\mathrm{r}_{0}$ equal to $10 \mathrm{~km}$ (see Fig. 7c). In addition, the western coast is not included in the quiescence. With $\mathrm{r}_{0}$ equal to $30 \mathrm{~km}$ or $35 \mathrm{~km}$ the extension ranges from $12^{\circ}$ to $15^{\circ}$ in longitude and with $\mathrm{r}_{0}$ equal to $10 \mathrm{~km} 12.5^{\circ}$ to $13.5^{\circ}$, not including the eastern coast.

\section{$<$ Figure 8 here>}

The map presented by Di Giovambattista and Tyupkin (2004) for Palermo earthquake was obtained in the same time period used in this paper. However only a small study area is analyzed, and the spatial extension of the quiescence areas cannot be compared.

\subsection{Development of RTL $_{\text {surv }}$}

Previously, quiescence zones had been found for most of the earthquakes analyzed, but the time interval adopted was chosen as the year when the RTL at the epicenter of the earthquake had a minimum. This is an a-posteriori choice that can be done only after that the epicenter is known. In 
addition, also the $\mathrm{r}_{0}$ and $\mathrm{t}_{0}$ parameters depend on RTL calculated at the epicenter and, therefore, on epicenter position. In this paper, and based on the promising results shown above, I propose a new approach for a continuous survey of the catalogue that can be done before the occurrence of the earthquake.

In developing the proposed method I considered the following facts:

1. Most considered earthquakes are preceded by one or more quiescences.

2. From the start of the quiescence to the earthquake there is a time interval ranging from 0.6 to 4 years (see Table 4). These results are similar to many others in the literature (see Sobolev and Tyupkin 1997, 1999, 2000, Di Giovambattista and Tyupkin 2000, 2004, Huang et al. 2001, 2002, Huang 2006; Chen and Wu 2006, a partial review of previous results can be found in Huang 2004), and therefore can be considered general.

3. Only $1 / 4$ of the analyzed earthquakes present an activation of seismicity, while the $92 \%$ present a quiescence. Therefore only the quiescence and not the activation can be regarded as a useful precursor in this study (see also Huang 2004 and references within).

4. Even if the quiescence can be detected for different values of $r_{0}$ and $t_{0}$, its beginning and its end time are parameter dependent.

5. RTL mapping methods existing in literature need an a-priori choice of the time period to be analyzed. Wrong choices of the period, if $\mathrm{RTL}_{\text {min }}$ method is adopted, may move the analysis into a time period where there is no quiescence, and supply non-negative values in the area where the epicenter will be. The Q method is even more sensitive to the choice of the time window, because if it contains both the quiescence and a successive activation, negative and positive values of the RTL can cancel each other, supplying positive or null values to the RTL map in the area of the future earthquakes.

The last point seems to indicate a slightly better performance of $\mathrm{RTL}_{\min }$ instead of $\mathrm{Q}$. However, the advantage of the $\mathrm{Q}$ method is that it takes into account the whole analyzed time 
period, while $\mathrm{RTL}_{\min }$ is sensitive to short duration spikes of the signal that can be due to casual fluctuation or inaccuracy in earthquakes locations.

Summarizing all the previous results and considerations I have developed a method that:

1. Considers all the potential times of quiescence before the earthquake

2. Neglects activation phases

The method, named, $\mathrm{RTL}_{\text {surv }}$, is calculated at every node of a grid of the investigated area and defined in the following way:

$$
R T L_{\text {surv }}(j)=\frac{1}{N} \sum_{i=1}^{N} R T L(i, j) \vartheta(R T L(i, j))
$$

where

$$
\vartheta(R T L(i, j))=\left\{\begin{array}{l}
1 \quad \text { if } \operatorname{RTL}(i, j)<0 \\
0 \quad \text { otherwise }
\end{array}\right.
$$

$\operatorname{RTL}(i, j)$ is the RTL calculated at node $j$ at time $i, \operatorname{RTL}_{\text {surv }}(\mathrm{j})$ is calculated at the $j^{\text {th }}$ node of the grid and $N$ in the number of data points of RTL in the time interval chosen for the analysis. In this work, a time step of 10 days is chosen. The grid cells are of $10 \times 10 \mathrm{~km}$. In accord with the previous results, the time interval chosen is 4 years long and ends with the time where the forecast starts. The forecast is valid for six months, and then it is repeated. An earthquake is considered corresponding to a quiescence zone if its distance from the nearest quiescence cell is smaller or equal to $2 \varepsilon+L / 2$, where $L$ is the cell dimension (10 $\mathrm{km}$ in this case). In order to automatically avoid inclusion of unstable results in the maps, for each cell $j$, RTL, and therefore $\operatorname{RTL}_{\text {surv }}(j)$, is calculated only if at least 50 earthquakes are localized inside a radius of $2 \mathrm{r}_{0}$ from the node in the time period from the start of the catalogue until the time of calculation (see also section 4.1). In addition, cells with $\mathrm{RTL}_{\text {surv }}>-0.5$ are not considered as quiescence cells (see Section 4.2). 


\section{Alarms and false alarms}

Due to the bad performances of RTL using L\&G catalogue in NE Italy (see section 4.1) the analysis in this area has been done by using NEI catalogue. The method has been tested separately on declustered L\&G and NEI catalogues on two contiguous regions shown in Fig. 9a. The analysis of the $L \& G$ catalogue is aimed at detecting seismic quiescence before the earthquakes with $M_{L} \geq 4$ and depth $<100 \mathrm{~km}$ in the time interval $1^{\text {st }}$ January $1994-31^{\text {st }}$ December 2004; the analysis of the NEI catalogue is aimed at detecting seismic quiescence before $M_{D} \geq 3.9$ (corresponding approximately to $\mathrm{M}_{\mathrm{L}} \geq 4$ - see equation 12) earthquakes with depth $<100 \mathrm{~km}$ in the time interval $1^{\text {st }}$ January $1998-31^{\text {st }}$ December 2004. The forecast has been done every 6 months and is valid for 6 months or more. The value of the completeness magnitude for $L \& G$ catalogue has been set to $\mathrm{M}_{\mathrm{L}}=2.4$ until the end of 2002 and $\mathrm{M}_{\mathrm{L}}=2.6$ for the last two years because the instrumental bulletin has higher completeness magnitude (see Fig. 3b); for the NEI catalogue a completeness value of $M_{D}=2.4$ has been adopted (see Fig. 3a).

\section{$<$ Figure 9 here $>$}

One open problem is the choice of parameters $r_{0}$ and $t_{0}$. For $t_{0} I$ choose simply the mean of the values listed in Table 3 , that is $t_{0}=0.9$ years. Ideally, for the choice of $r_{0}$, a method like Chen and Wu one, perhaps with a threshold on the maximum value of $r_{0}$, should be applied. However, besides being computationally intensive, this choice would cause different vales of $r_{0}$ in different regions of the same map, and not all the points would be weighted evenly. On the other side, selecting the same value of $r_{0}$ for large regions, like, e.g., all Italy, engenders some problems. Small values of $r_{0}$ can lead to unstable RTL in regions where few earthquakes are recorded, due to the small number of data available. Conversely, large values of $r_{0}$ cause a large quiescence area, reducing the value of the method. The performances have been tested for both the L\&G and NEI catalogues in the respective analysis areas by varying the value of $r_{0}$ from 10 to $30 \mathrm{~km}$ with steps of $5 \mathrm{~km}$. The percentage of earthquakes preceded by a quiescence (found earthquakes) with $M_{L} \geq 4$ is plotted in 
Fig. 10a and 11a respectively, and compared with the percentage of quiescence area with respect to the whole area analyzed by the catalogue (Fig. 10b and 11b). An approximately linear increase of the quiescence area with the radius is detected for both catalogues; while using the NEI catalogue all the earthquakes with magnitude greater than 4 are found also with the minimum tested radius $\left(r_{0}=10 \mathrm{~km}\right.$, see Fig. 11a) the percentage of found earthquakes is smaller using L\&G catalogue and increases approximately linearly with radius.

\section{<Figure 10 and 11 here>}

Fig. 12 shows the distribution of found earthquakes (white symbols) and of earthquakes for which no seismic quiescence was detected (lost earthquakes - black symbols) setting $\mathrm{r}_{0}=10 \mathrm{~km}$ (Fig. 12a) and $\mathrm{r}_{0}=30 \mathrm{~km}$ (Fig. 12b) in the whole time period 1994-2004. Stars represent earthquakes with magnitude $M_{L}>5$, dots earthquakes with magnitude $4<M_{L} \leq 5$. Fig. 12a shows that, using $r_{0}=10$ $\mathrm{km}$, a quiescence is detected for a large percentage of the earthquakes $(66 \%$ of the earthquakes with magnitude greater than 4 , all the earthquakes with magnitude greater than 5) in the central and the southern part of Italian peninsula and Sicily (zone 2 in Fig. 9b); in addition, a quiescence is detected before all earthquakes in Northeastern area of Italy (zone 4 in Fig. 9b; the one analyzed by the NEI catalogue). For the rest of Italy no quiescence is detected before the earthquakes. This is due to the instability of RTL for $r_{0}=10 \mathrm{~km}$ in regions where the recorded seismicity is low; the value of RTL $_{\text {surv }}$ in these areas could not be evaluated. For zone 3 of Fig. 9b, containing Sardinia and Corsica islands and the most of Tyrrhenian Sea, no reliable value of $r_{0}$ can be applied to obtain a stable RTL, due to the very small number of recorded earthquakes (in a rectangle with vertices (N latitude, E longitude $)=\{(42,9),(42,11),(40,11),(40,9))\}$ around the larger magnitude seismicity in the area , the number of recorded earthquakes from 1994 to 2004 is 14). For most of the northern part of Italy, (zone 1 in the Fig. 9b) it is necessary to use $r_{0}=30 \mathrm{~km}$ to obtain the same performance that is obtained in the central-south Italy (zone 2) with $r_{0}=10 \mathrm{~km}$ (see Fig. 12b). An analysis by macro-areas is therefore adopted with $\mathrm{RTL}_{\text {surv }}$ method, neglecting the area 3 , where no precursor detection is possible using RTL, until a larger number of earthquakes are recorded in that area. 


\section{$<$ Figure 12 here $>$}

Table 7 shows the obtained performances of the method in terms of percentage of area of the seismic quiescence (alarm area) with respect to the whole area of the region analyzed, and in terms of percentage of found earthquakes, depending on the magnitude. The analysis is done by evaluating the RTL $\mathrm{Rurv}_{\text {every }} 6$ months and considering the earthquakes which occurred during the 6 months following the forecast. In order to have a more complete analysis of the method performance, it would be necessary to understand what percentage of the alarm area should be considered a true alarm (the earthquake happens in the alarm area) and what a false alarm. In order to do this, the concept of "false alarm" should be studied in detail. A draft definition of false alarm could be "a false alarm is a detected quiescence region where no earthquake with $\mathrm{M} \geq 4$ happens during the six months following the forecast". However, since the extension of the quiescence areas grows with increasing the radius $r_{0}$, different quiescence areas merge together, and the number of false alarms defined in the previous way decreases, even if the overall alarm area increases. For this reason, I propose an alternative definition of true and false alarm, analyzing separately all the cells of a grid: "A quiescence cell is considered a true alarm if an earthquake with $M_{L} \geq 4$ occurs within a distance $2 \varepsilon+\mathrm{L} / 2+2 \mathrm{r}_{0}$ during the six months following the forecast; otherwise, it is a false alarm". This definition takes into account the influence of $r_{0}$ on RTL and the inaccuracy of location due to the catalogue and the grid discretization. Table 7 lists the percentage of true and false alarms for the zones 1, 2 and 4. From the table, it can be inferred that the percentage of false alarms is high with respect to the whole alarm area. However, if the whole monitored region is considered, the false alarm area is smaller or equal to the $15.5 \%$ (see Table 7); considering that and at least $66 \%$ of $\mathrm{M} \geq 4$ and $100 \%$ of $M>5$ earthquakes are found, a good correlation between seismic quiescence and large to medium earthquakes can be deduced. 


\section{Conclusions}

In this paper, the seismicity quiescence before the larger Italian earthquakes from 1994 to the end of 2004 has been analyzed. In particular, the RTL algorithm has been applied. The Chen and $\mathrm{Wu}$ (2006) method allows me to obtain $\mathrm{r}_{0}$ and $\mathrm{t}_{0}$ parameters for RTL calculated at the epicenter of large earthquakes. Using these parameters on $12 \mathrm{M}>5$ earthquakes which occurred in Italy in the time period from January 1994 to December 2004, a quiescence phase is detected in $92 \%$ of the cases, while only $25 \%$ of the earthquakes are preceded by an activation phase. The duration of the quiescence and the time shift from the end of the quiescence to the earthquake time have been evaluated and ranges from 0.6 to 3 years and 0 to 2.9 years respectively, with a time interval from the start of the quiescence to the main shock ranging from 0.6 to 4 years. The obtained parameters have been applied also to the mapping of the quiescence region before the earthquake. The quiescence regions appear in some cases very large, due to the high value of $r_{0}$. For this reason, a simple method for the best choice of the parameters is proposed and tested on the M $>5$ earthquakes. The results are improved for 10 of the 11 cases in which the earthquake was preceded by a quiescence, and remain unchanged in the other. The quiescence regions detected by this method are characterized by linear dimensions ranging 50 to $450 \mathrm{~km}$ with mean value $164 \mathrm{~km}$.

A survey method based on RTL for the whole Italy analysis is proposed. The aim of the method, named RTL $L_{\text {surv }}$, is to make a survey of the Italian area, in order to detect seismic quiescence zones that may give rise to large earthquakes. The advantage of the method is that it is not necessary to define a-priori the analysis time window. $\mathrm{RTL}_{\text {surv }}$ has been tested on declustered catalogues for the earthquakes with $\mathrm{M}_{\mathrm{L}} \geq 4$ in the time interval $1^{\text {st }}$ January 1994-31 ${ }^{\text {st }}$ December 2004. The Italian area was divided into 4 zones with different characteristics of the recorded seismicity. One of the zones (North and Central Tyrrhenian sea) is characterized by too low a number of recorded earthquakes for the analysis. For each of the other three zones a parameter $r_{0}$ was found for which at least the $66 \%$ of the earthquakes with $M_{L}>4$ and all the earthquakes with $M_{L}>5$ were 
preceded by a detected seismic quiescence. The overall alarm area ranges from $8.7 \%$ to $18.4 \%$ of the whole analyzed region area, depending on the zone analyzed and on parameter $\mathrm{r}_{0}$.

Even if the results found in this paper are encouraging, I wish to emphasize which are the limits of the method:

1. The time shift between the detection of a quiescence and the earthquake can be long and therefore it has been necessary to select a long time analysis for the RTL $\mathrm{Rurv}_{\text {( }}$ ( years). This fact, together with the impossibility of discriminating between an isolated $\mathrm{M} \geq 4$ mainshock and a swarm of $M \geq 4$ earthquakes during even tens of months, means that after a $M \geq 4$ earthquake the surrounding region may remain an alarm area for a long time, even if no earthquake follows, generating false alarms.

2. The area covered by the quiescence zone can be large, especially in regions characterized by a low recorded seismicity, not allowing us to have indications for a reasonable economic planning of constructions, timely preparation of a potential future damage and correct land use.

\section{Acknowledgments}

I would like to thank Gianni Bressan, Pier Luigi Bragato and Laura Peruzza for their valuable discussions and suggestions. This research has benefited from funding provided by the Italian Presidenza del Consiglio dei Ministri - Dipartimento della Protezione Civile (DPC). Scientific papers funded by DPC do not represent its official opinion and policies. The management of the Seismometric Network of Friuli-Venezia Giulia is financially supported by the Civil Protection of the Regione Autonoma Friuli-Venezia Giulia. I'm grateful to all the OGS staff of the Dipartimento Centro Ricerche Sismologiche at Udine for managing the network. 


\section{References}

Bendat, J. S. and Piersol, A. G., Random Data: Analysis and Measurements Procedures. (John Wiley and Sons, New York 2000).

Brehm D. J., Braile L. W. (1998), Intermediate-term Prediction Using Precursory Events in the New Madrid Seismic Zone, Bull. Seismol. Soc. Am. 88, 564-580.

Bressan, G., Kravanja, S., Franceschina, G., (2007), Source parameters and stress release of seismic sequences occurred in the Friuli-Venezia Giulia region (Northeastern Italy) and in Western Slovenia, Phys. Earth Planet. Inter. 160, 192-214

Bufe, C.G., Varnes D.J. (1993), Predictive Modeling of the Seismic Cycle of the Greater San Francisco Bay Region, J. Geophys. Res. 98, 9871-9883.

Castello, B., Selvaggi, G., Chiarabba, C., Amato, A. (2005), Catalogo della sismicità italiana - CSI 1.0 (1981-2002).

Chen, C. C, Wu, Y. X. (2006), An improved region-time-length algorithm applied to the 1999 Chi-Chi, Taiwan earthquake, Geophys. J. Int. 166, 1144-1147.

CSTI Working Group (2001) Catalogo strumentale dei terremoti Italiani dal 1981 al 1996, Version 1.0. CD-ROM, Clueb, Bologna, also available at: http://ibogfs.df.unibo.it/user2/paolo/www/gndt/Versione1_0/Leggimi.htm

CSTI Working Group (2004) Catalogo strumentale dei terremoti Italiani dal 1981 al 1996, Version 1.1, available at:

http://ibogfs.df. unibo.it/user2/paolo/www/gndt/Versione1_1/Leggimi.htm

Di Giovambattista, R., Tyupkin, Y. S. (1999), The fine structure of the dynamics of seismicity before $\mathrm{M} \geq 4.5$ earthquakes in the area of Reggio Emilia (Northern Italy), Annali di Geofisica 42, 897-909. 
Di Giovambattista, R., Tyupkin, Y. S. (2000), Spatial and temporal distribution of the seismicity before the Umbria-Marche September 26, 1997 earthquakes, Journal of Seismology 4, 589-598.

Di Giovambattista, R., Tyupkin, Y. S. (2004), Seismicity patterns before the M=5.8 2002, Palermo (Italy) earthquake: seismic quiescence and accelerating seismicity, Tectonophysics 384, 243-255.

Franceschina, G., Kravanja, S., Bressan, G. (2006), Source parameters and scaling relationships in the Friuli-Venezia Giulia (Northeastern Italy) region, Physics of the Earth and Planetary Interiors 154, 148-167.

Gasperini, P., Ferrari, G. (2000), Deriving numerical estimates from descriptive information: the computation of earthquake parameters, Ann. Geofis. 43, 729-746.

Gentili, S., Bressan, G. (2007), Seismicity patterns before MD $\geq 4.1$ earthquakes in the FriuliVenezia Giulia (northeastern Italy) and western Slovenia areas, Bollettino di Geofisica Teorica ed Applicata 48, 33-51.

Gentili, S., Bressan, G. (2008), The partitioning of radiated energy and the largest aftershock of seismic sequences occurred in the northeastern Italy and western Slovenia, Journal of Seismology 12, 343-354.

Habermann, R. E. (1987), Man-made changes of Seismicity rates, Bull. Seism. Soc. Am. 77, 141-159.

Huang, Q. (2004), Seismicity pattern changes prior to large earthquakes-An approach of the RTL algorithm,Terrestrial, Atmospheric and Oceanic Sciences, 15, 469-491.

Huang, Q. (2006), Search for reliable precursors: A case study of the seismic quiescence of the 2000 western Tottori prefecture earthquake, J. Geophys. Res. 111, B04301, doi:10.1029/2005JB003982.

Huang, Q., Nagao, T. (2002), Seismic quiescence before the $2000 \mathrm{M}=7.3$ Tottori earthquake, Geophys. Res. Lett. 29:10.1029/2001GL013835. 
Huang, Q., Öncel, A. O., Sobolev, G. A. (2002), Precursory seismicity changes associated with the Mw= 7.41999 August 17 Izmit (Turkey) earthquake, Geophys. J. Int. 151, 235- 242.

Huang, Q., Sobolev, G. A. (2002), Precursory seismicity changes associated with the Nemuro Peninsula earthquake, January 28, 2000, Journal of Asian Earth Sciences, 21, 135-146.

Huang, Q., Sobolev, G. A., Nagao, T. (2001), Characteristics of the seismic quiescence and activation patterns before the $\mathrm{M}=7.2$ Kobe earthquake, January 17, 1995, Tectonophysics, 337, 99-116.

Jiang, H., Hou, H., Zhou, H., Zhou, C. (2004), Region-time-lenght algorithm and its application to the study of intermediate-short term earthquake precursor in North China, Acta Seismologica Sinica, 17, 164-176.

Kanamori, H., Anderson, D. L. (1975), Theoretical basis of some empirical relations in seismology, Bull. Seism. Soc. Am. 65, 1073-1095.

Knopoff, L. (2000), The magnitude distribution of declustered earthquakes in Southern California, Proc. Natl. Acad. Sci. USA, 97, 11880-11884.

Lee, W. H. K. and Lahr, J. C. (1975), HYPO71 (revised): a computer program for determining hypocenter, magnitude and first motion pattern of local earthquakes, U.S. Geol. Surv. Open File Rep. 75-311.

Lolli B., Gasperini, P. (2003), Aftershocks hazard in Italy Part I: Estimation of timemagnitude distribution model parameters and computation of probabilities of occurrence, Journal of Seismology 7, 235-257.

Lolli, B., Gasperini, P. (2006), Comparing different models of aftershock rate decay: The role of catalog incompleteness in the first times after main shock, Tectonophysics 423, 43-59.

Marcellini, M., Milani, D. (2003), Valutazione della sismicità temporale del Friuli-Venezia Giulia Internal Report CNR Istituto per la dinamica dei processi ambientali, Milan, Italy. 
Pace, B., Peruzza, L., Lavecchia, G., and Boncio, P. (2006), Layered Seismogenic Source Model and Probabilistic Seismic-Hazard Analyses in Central Italy, Bull. Seism. Soc. Am. 96, 107132.

Papadopoulus, G. A., Voidomatis, P. (1987), Evidence of periodic seismicity in the inner Aegean seismic zone, Pure Appl. Geophys. 125, 613-628.

Postpischl, D. (Ed.) (1985), Catalogo dei terremoti italiani dall'anno 1000 al 1980. Quaderni della Ricerca Scientifica, 114 2B, CNR, Rome.

Priolo, E., Barnaba, C., Bernardi, P., Bernardis, G., Bragato, P. L., Bressan, G., Candido, M., Cazzador, E., Di Bartolomeo, P., Durì, G., Gentili, S., Govoni, A., Klinc, P., Kravanja, S., Laurenzano, G., Lovisa, L., Marotta, P., Michelini, A., Ponton, F., Restivo, A., Romanelli, M., Snidarcig, A., Urban, S., Vuan, A., Zuliani, D. (2005), Seismic monitoring in Northeastern Italy: a ten-year experience, Seismological Research Letters 76, 451-460.

Reasenberg, P. A. (1985), Second-order moment of Central California seismicity, 19691982, J Geophys Res. 90, 5479-5495.

Rebez, A., Renner, G. (1991), Duration magnitude for the northeastern Italy seismometric network. Boll. Geof. Teor. Appl. 33, 177-186.

Rong, D., Li, Y. (2007), Estimation of Characteristic Parameters in region-time-length Algorithm and Its Application, Acta Seismologica Sinica 20, 265-272.

Scholz, C. H. (1988), Mechanisms of seismic quiescences, Pure Appl. Geophys. 126, 701718.

Schorlemmer D. and Woessner J. (2008), Probability of Detecting an Earthquake, Bull. Seism. Soc. Am. 98, 2103-2117.

Selvaggi, G., Deschamps, A., Ripepe, M., and Castello, B. (2002), Waveforms, arrival times and locations of the 1997 Colfiorito (Umbria-Marche, Central Italy) aftershocks sequence, Quad. Geofis. 21, 6 CDROMs. 
Sobolev, G. A. (2000), Precursory phases of large Kamchatkan earthquakes, Volc. Seis. 21, 497-509.

Sobolev, G. A., Tyupkin, Y. S., New method of intermediate-term earthquake prediction, in European Seismological Commission XXV General Assembly "Seismology in Europe". Reykjavik, Iceland. 9-13 September 1996, pp. 229-234.

Sobolev, G. A., Tyupkin Y. S. (1997), Low seismicity precursors of large earthquakes in Kamchatka,. Volc. Seis. 18, 433-446.

Sobolev, G. A., Tyupkin, Y. S., Zavialov, A. (1997), Map of Expectation Earthquakes Algorithm and RTL Prognostic Parameter: Joint Application. The 29th General Assembly of IASPEI, Thessaloniki, Greece, Abstracts, 77.

Sobolev, G. A., Tyupkin, Y. S. (1999), Precursory Phases, seismicity precursors and earthquake prediction in Kamchatka, Volc. Seis. 20, 615-627.

Wiemer, S. (2001), A software package to analyze seismicity: ZMAP, Seism. Res. Let. 72(2), 373-382.

Wiemer, S., Wyss, M. (1994), Seismic quiescence before the Landers (M=7.5) and Big Bear (M=6.5) 1992 earthquakes, Bull. Seism. Soc. Am. 84, 900-916.

Woessner, J., Wiemer, S. (2005), Assessing the Quality of Earthquake Catalogues: Estimating the Magnitude of Completeness and Its Uncertainty, Bull. Seism. Soc. Am. 95, 684-698.

Wyss, M. (1991), Reporting history of the central Aleutians seismograph network and the quiescence preceding the 1986 Andreanof Island earthquake. Bull. Seism. Soc. Am. 81, 1231-1254.

Wyss, M., Habermann, R. E. (1988), Precursory seismic quiescence. Pure and Applied Geophysics 126, 701-718. 


\section{Figure Captions}

Figure 1: Cumulative number of earthquakes with $M_{D}>0$ in (a) the NEI catalogue and (b) the L\&G catalogue. Vertical dashed lines: the time window of data recording interruption for the NEI catalogue; black continuous line: catalogue before the declustering; black arrows: increases of seismicity; grey continuous line: catalogue after the modified Knopoff algorithm declustering; black dashed line: catalogue after the Reasenberg declustering using default parameters; grey dashed line: catalogue after the Reasenberg declustering using Lolli and Gasperini parameters.

Figure 2: Seismic moment $\mathrm{M}_{0}$ as a function of duration magnitude $\mathrm{M}_{\mathrm{D}}$ in NE Italy area. Data from Franceschina et al 2006 and Bressan et al. 2007.

Figure 3: Changes with time of the magnitude of completeness for (a) NEI catalogue (duration magnitude) (b) Lolli and Gasperini catalogue (local magnitude).

Figure 4: RTL calculated at the epicenters of analyzed earthquakes using the parameters listed in Table 3 (thick line) and standard parameters $\mathrm{r}_{0}=30 \mathrm{~km} \mathrm{t}_{0}=1$ year (thin grey line) until the midnight before the mainshock. Adopted declustering method: modified Knopoff algorithm. Epicenter location: (a) Gargano (Apulia) (b) Reggio Emilia (c) Umbria Marche (d) Kobarid (1998)

(e) Calabrian-Lucanian Apennines (f) Merano (g) Sernio Mountain (h) Palermo (i) Molise (l) Adriatic Sea (m) Kobarid (2004) (n) Garda Lake.

Figure 5: RTL calculated at the epicenters of NE Italy earthquakes using L\&G catalogue and the parameters $r_{0}$ and $t_{0}$ calculated by Chen and $\mathrm{Wu}$ method on the same catalogue. Epicenter location: (a) Kobarid (1998) $\mathrm{r}_{0}=35 \mathrm{~km} \mathrm{t}_{0}=1.8$ years (b) Sernio Mountain $\mathrm{r}_{0}=55 \mathrm{~km} \mathrm{t}_{0}=0.4$ years (c) Kobarid (2004) $\mathrm{r}_{0}=30 \mathrm{~km} \mathrm{t}_{0}=1.3$ years.

Figure 6: RTL calculated at the epicenters of analyzed earthquakes using the parameters listed in Table 3 (thick line) and standard parameters $\mathrm{r}_{0}=30 \mathrm{~km} \mathrm{t}_{0}=1$ year (thin grey line) until the midnight before the mainshock. Adopted declustering method: Reasenberg declustering algorithm with Lolli and Gasperini parameters. Epicenter location: (a) Gargano (Apulia) (b) Reggio Emilia (c) 
Umbria Marche (d) Kobarid (1998) (e) Calabrian-Lucanian Apennines (f) Merano (g) Sernio Mountain (h) Palermo (i) Molise (1) Adriatic Sea (m) Kobarid (2004) (n) Garda Lake.

Figure 7: Map of the RTL using the Q method (grayscale), $\mathrm{t}_{0}$ obtained by Cheng and $\mathrm{Wu}$ method and $r_{0}$ using minimum radius method (see Table 6) ). The white star represents the epicenter location for: (a) Gargano (Apulia) (b) Reggio Emilia (c) Umbria Marche (d) Kobarid (1998) (e) Calabrian-Lucanian Apennines (f) Merano (g) Sernio Mountain (h) Palermo (i) Molise (l) Adriatic Sea (m) Kobarid (2004) (n) Garda Lake.

Figure 8: Map of the RTL using the $\mathrm{Q}$ method, at the epicenter of Umbria Marche earthquake using $\mathrm{t}_{0}=0.6$ years and (a) $\mathrm{r}_{0}=35 \mathrm{~km}$ (b) $\mathrm{r}_{0}=30 \mathrm{~km}$.

Figure 9: Map of Italy with (a) regions analyzed by L\&G and NEI catalogues (b) Draft subdivision into macro-areas as a function of the number of recorded earthquakes.

Figure 10: Behaviour of $r_{0}$ for the $L \& G$ catalogue (see Fig. 9a): (a) Percentage of earthquakes with $M_{L} \geq 4$ for which a precursory quiescence is detected as function of parameter $r_{0}$ adopted (b) percentage of the area characterized by a detected seismic quiescence as function of parameter $\mathrm{r}_{0}$ adopted.

Figure 11: Behaviour of $r_{0}$ for the NEI catalogue (see Fig. 9a): (a) Percentage of earthquakes with $\mathrm{M}_{\mathrm{D}} \geq 3.9$ (corresponding approximately with $\mathrm{M}_{\mathrm{L}} \geq 4$ ) for which a precursory quiescence is detected as function of parameter $r_{0}$ adopted (b) percentage of the area characterized by a detected seismic quiescence as function of parameter $\mathrm{r}_{0}$ adopted.

Figure 12: Map of the earthquakes preceded by a detected quiescence (white symbols) and not (black symbols). Stars correspond to earthquakes with $M_{L}>5$, circles to earthquakes with $4 \leq \mathrm{M}_{\mathrm{L}} \leq 5$. (a) $\mathrm{r}_{0}=10 \mathrm{~km}$ (b) $\mathrm{r}_{0}=30 \mathrm{~km}$. 


\section{Table captions}

Table 1: All the earthquakes with $\mathrm{M}_{\mathrm{L}}>5$ listed in $\mathrm{L} \& \mathrm{G}$ and NEI catalogues. The earthquakes outlined in boldface are the ones analyzed in this paper. Lat and Lon: north latitude and east longitude of the main shock (degrees); $\mathrm{M}_{\mathrm{L}}(\mathrm{L} \& \mathrm{G})$ ) local magnitude as listed in $L \& G$ catalogue; $\mathrm{M}_{\mathrm{D}}$ (NEI): duration magnitude as listed in NEI catalogue.

Table 2: Analyzed earthquakes and adopted completeness magnitude. Catalogue: catalogue adopted for the analysis; Magnitude: type of magnitude listed; $\mathbf{M}_{\mathrm{c}}$ : completeness magnitude inside a circle of radius $100 \mathrm{~km}$ centered at the epicenter in the magnitude units of the adopted catalogue.

Table 3: The $t_{0}$ and $r_{0}$ values selected by Chen and $\mathrm{Wu}$ (2006) method and the corresponding peak values $p\left(t_{0}\right)$ and $p\left(r_{0}\right)$.

Table 4: Minimum $\left(\mathrm{M}_{\min }\right)$ and maximum $\left(\mathrm{M}_{\max }\right)$ magnitude threshold used for calculation for which the quiescence before the analyzed earthquakes is detected. Adopted magnitude threshold (completeness magnitude $\mathrm{M}_{\mathrm{c}}$ ) is shown for comparison.

Table 5: The characteristics of quiescences and activation phases detected by the RTL obtained at the epicenter of the analyzed earthquakes, using the parameters listed in Table 3 .

Table 6: Adopted parameters in RTL map construction by applying (i) Cheng and Wu method (ii) Threshold on $\mathrm{r}_{0}$ (iii) Minimum radius. For each choice, the corresponding quiescence anomaly linear dimension is listed.

Table 7: Performances of the RTL $\mathrm{R}_{\text {surv }}$ method on three zones shown in Fig. $9 \mathrm{~b}$. 
Figures

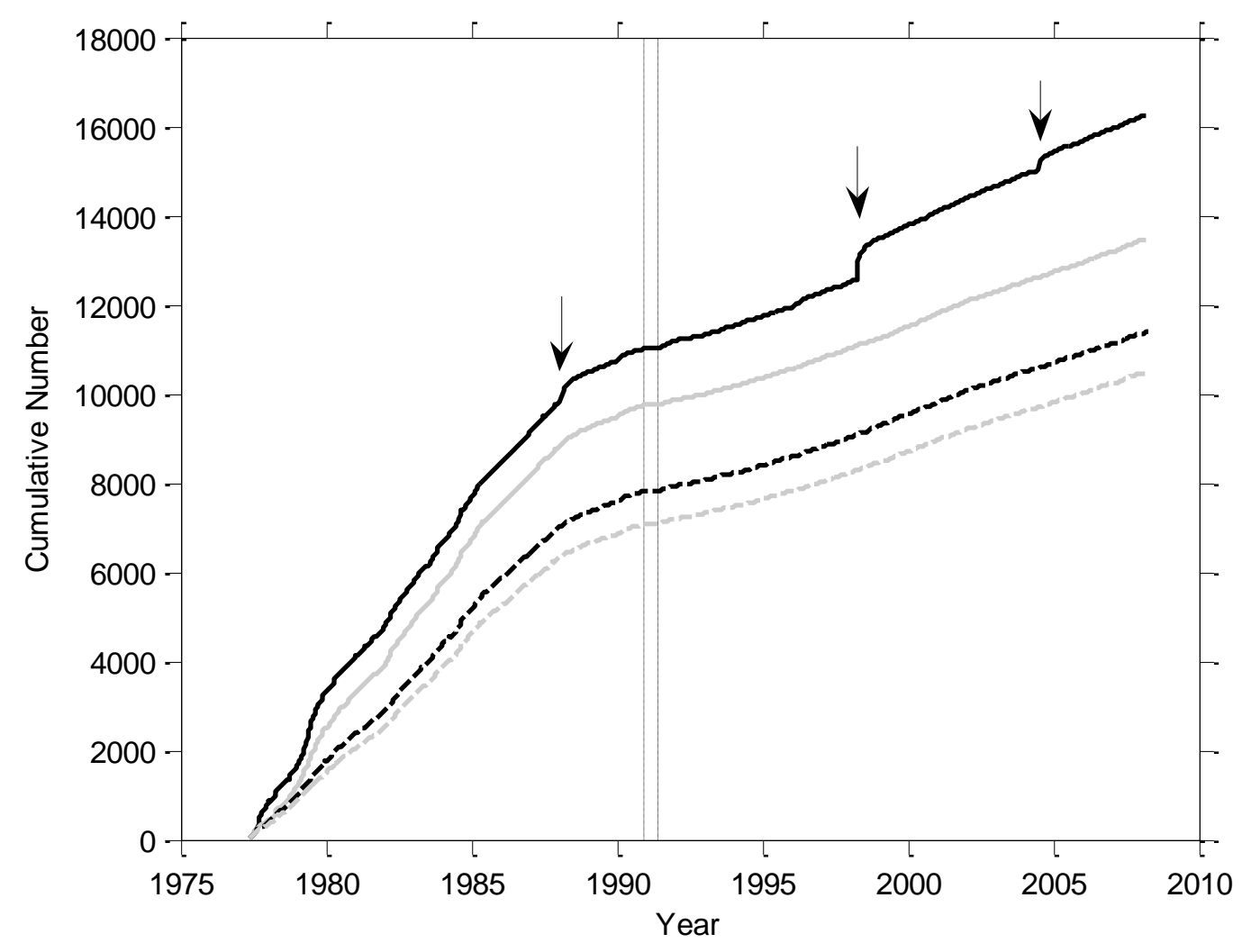

(a) 


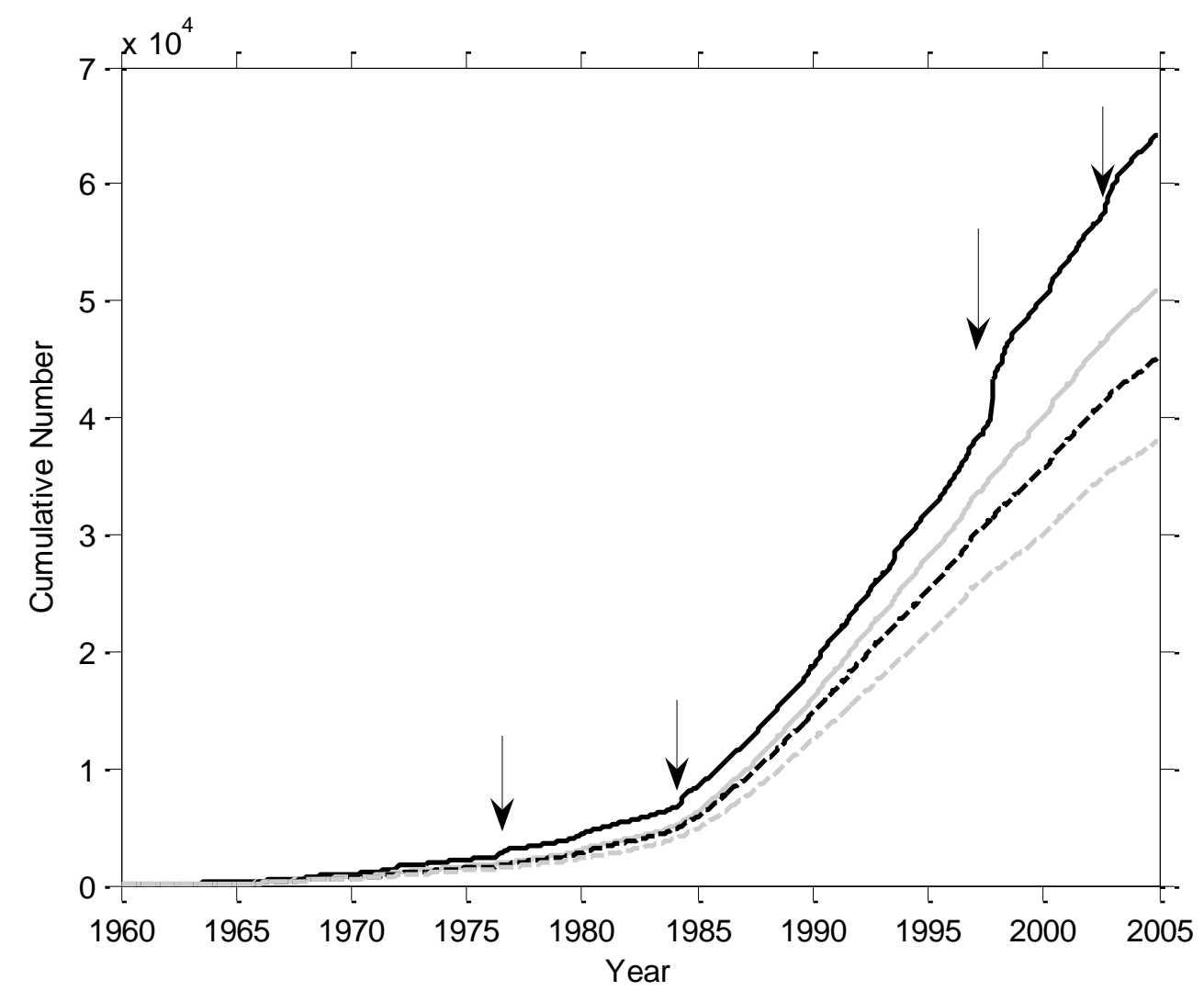

(b)

Figure 1 


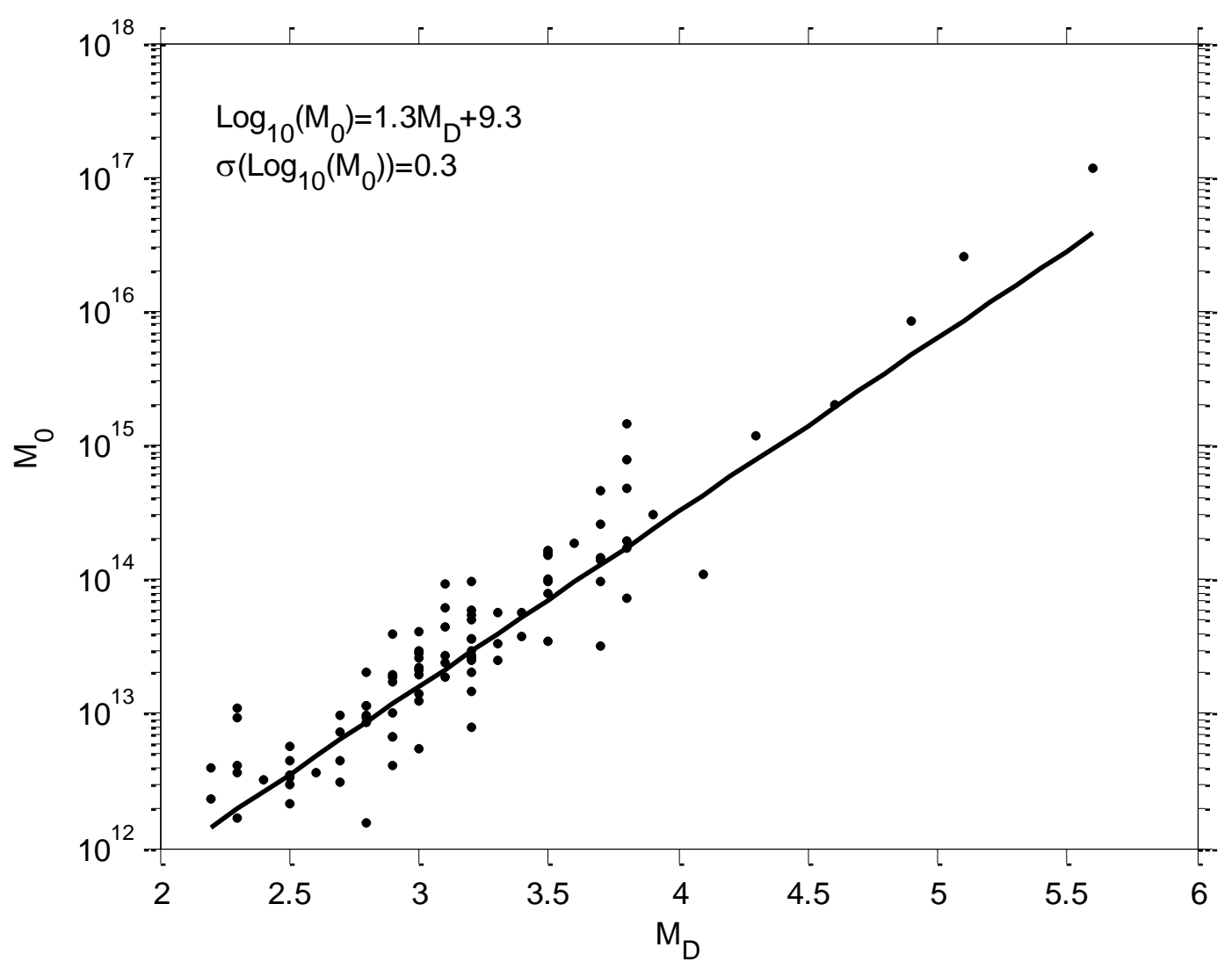

Figure 2 


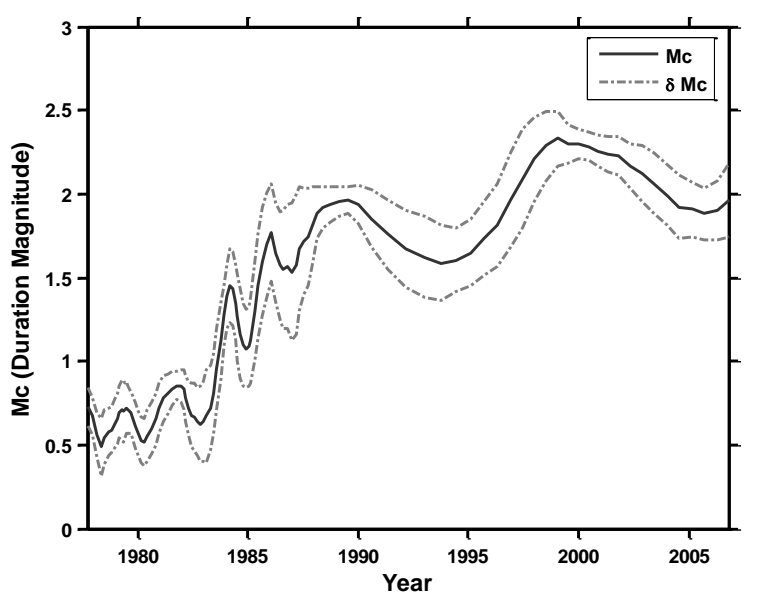

(a)

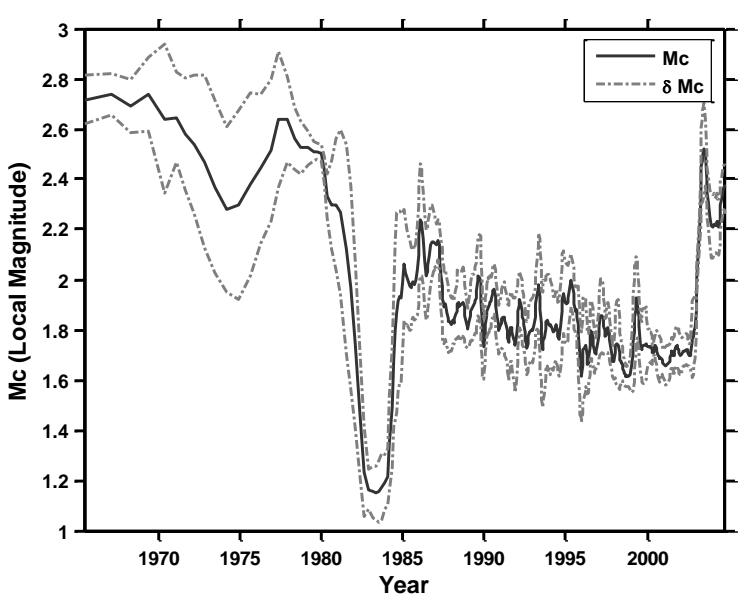

(b)

Figure 3 


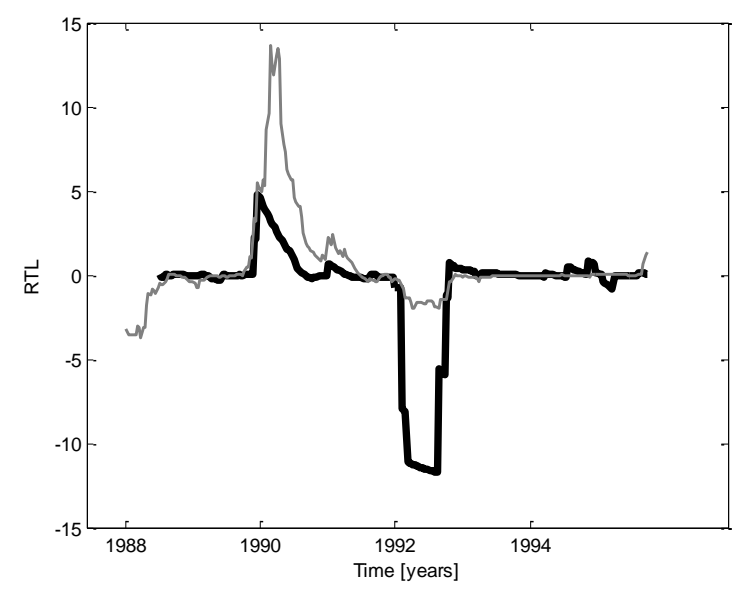

(a)

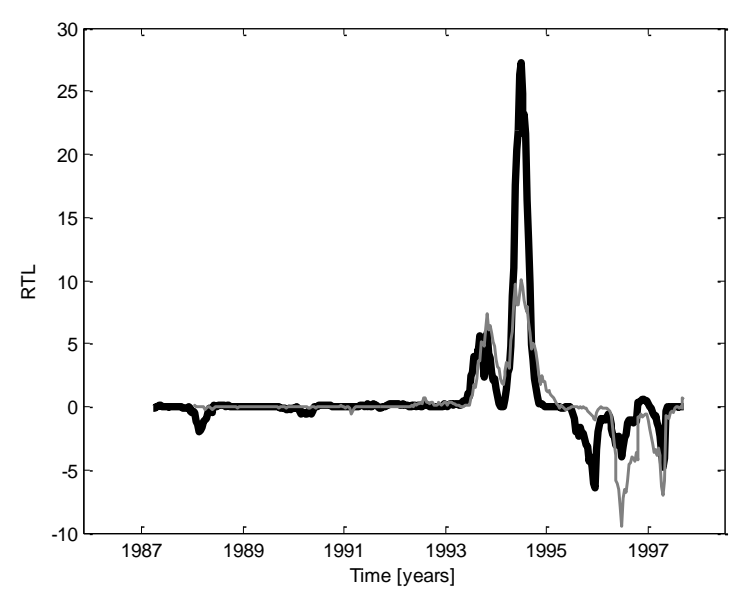

(c)

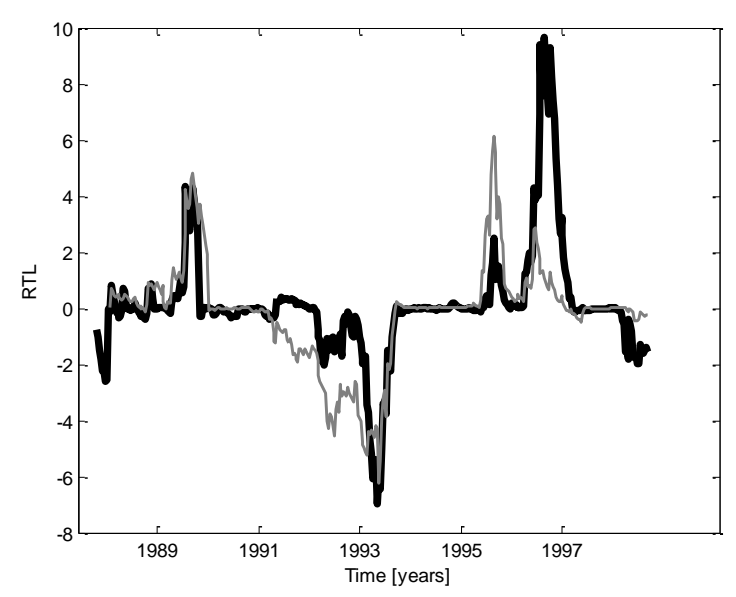

(e)

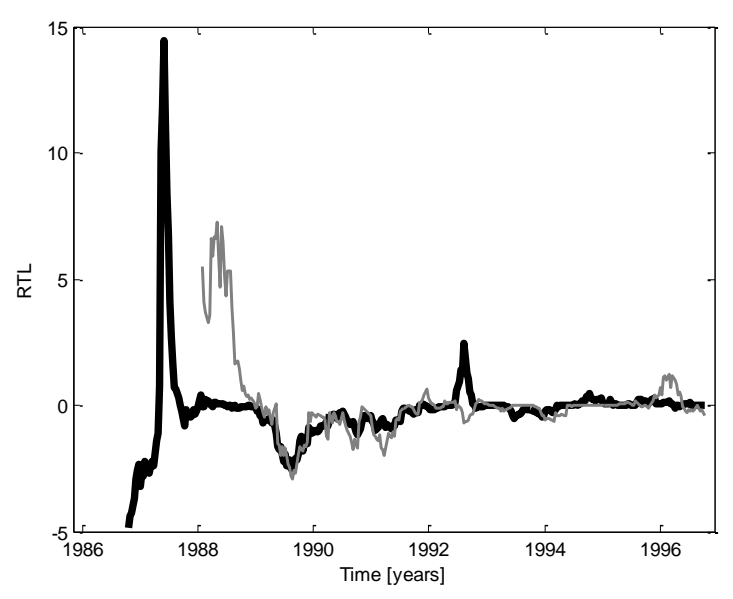

(b)

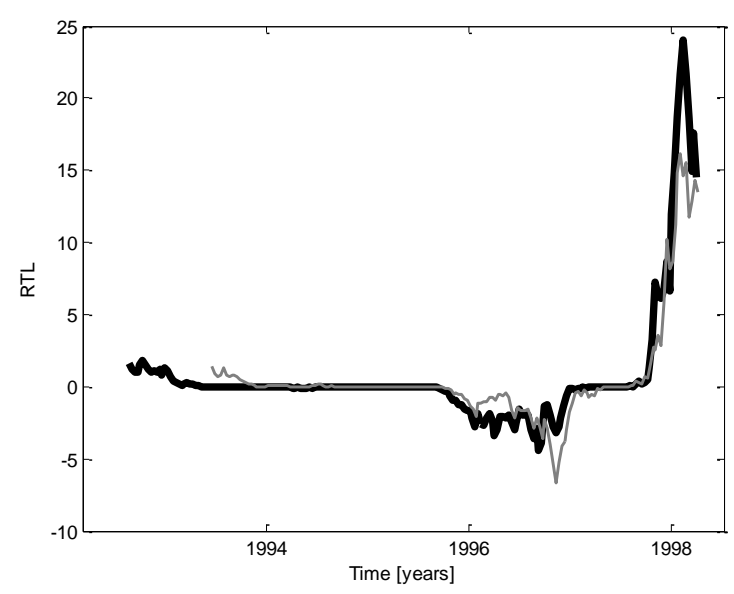

(d)

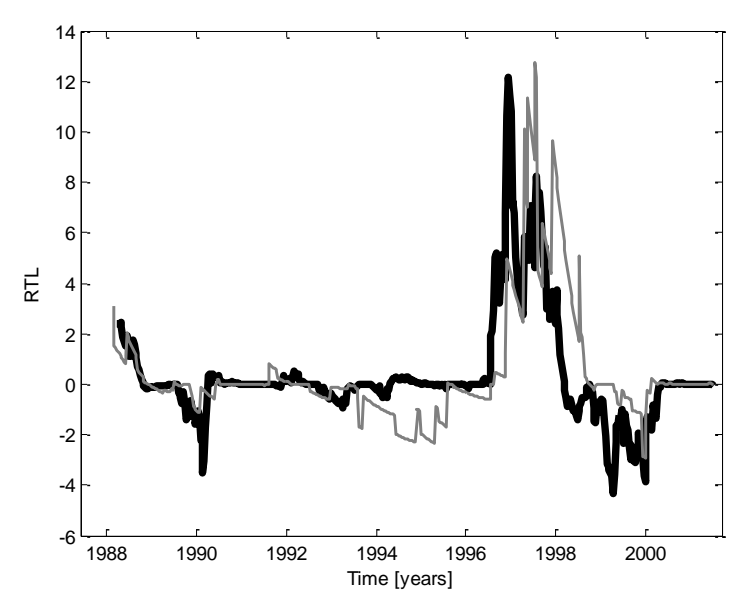

(f) 


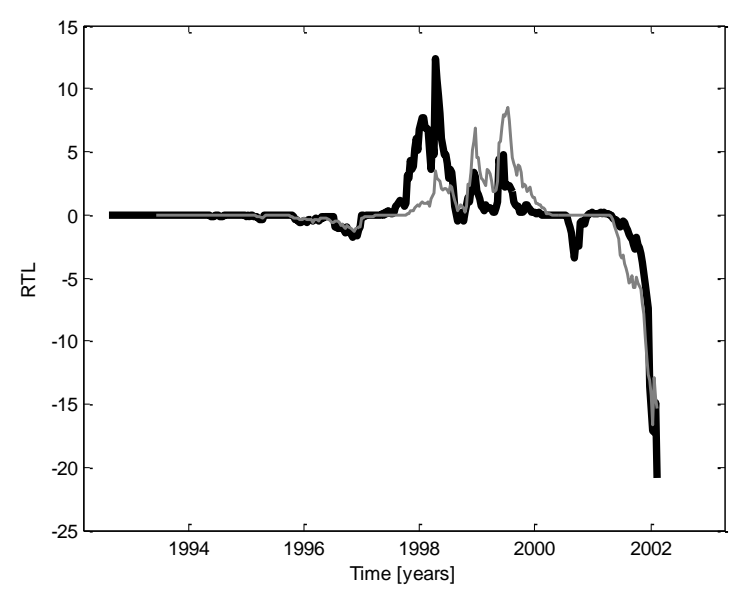

(g)

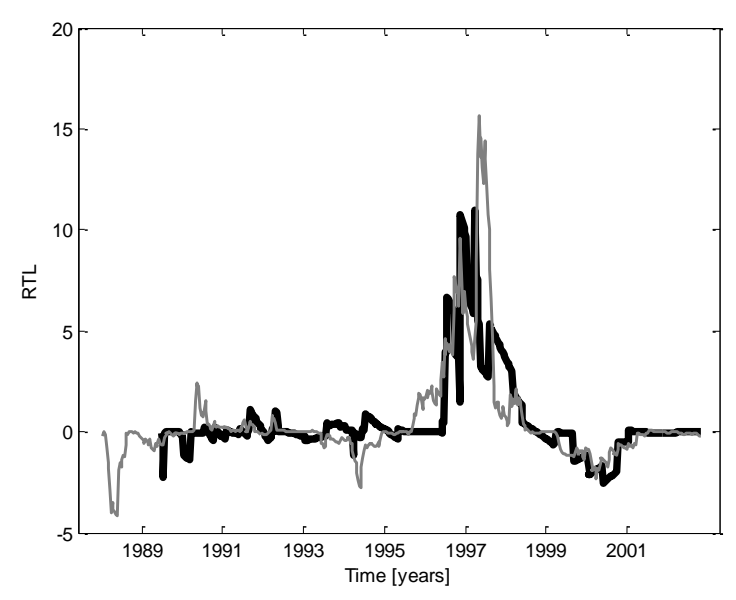

(i)

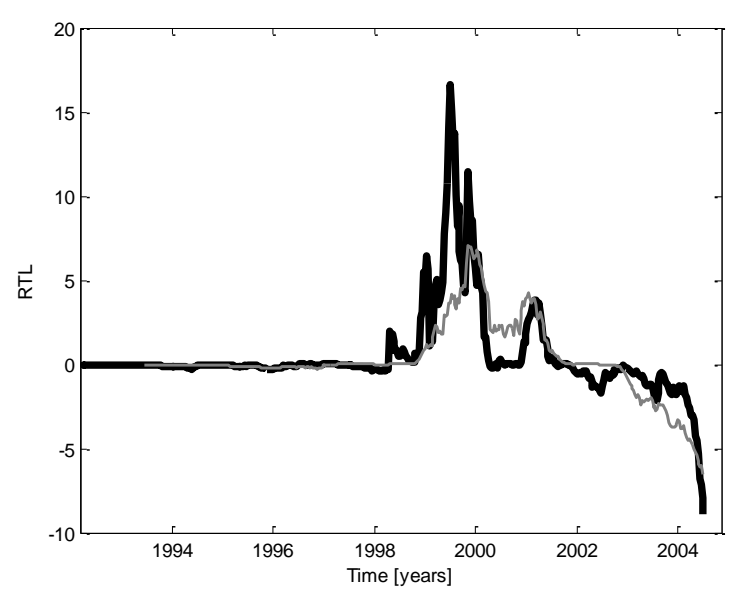

(m)

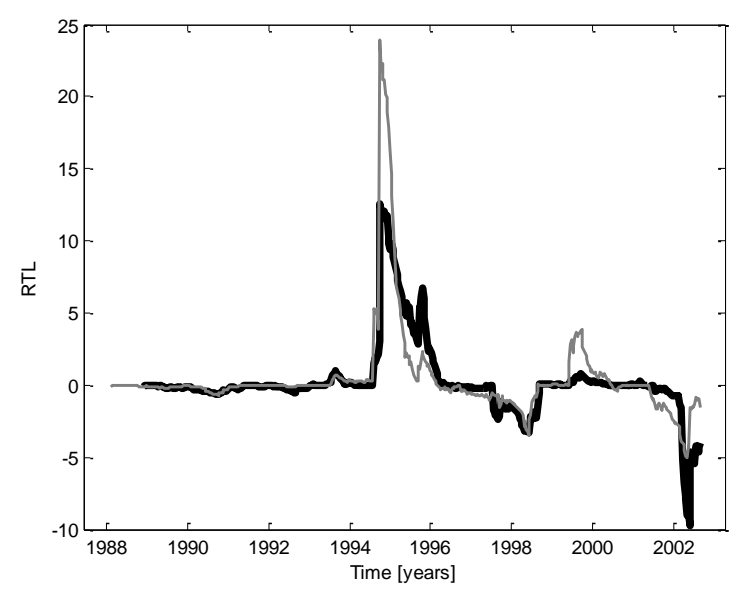

(h)

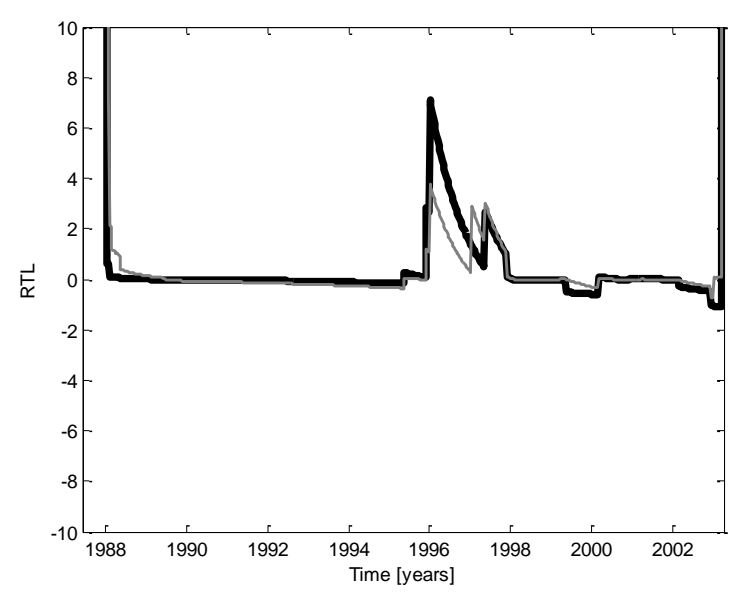

(1)

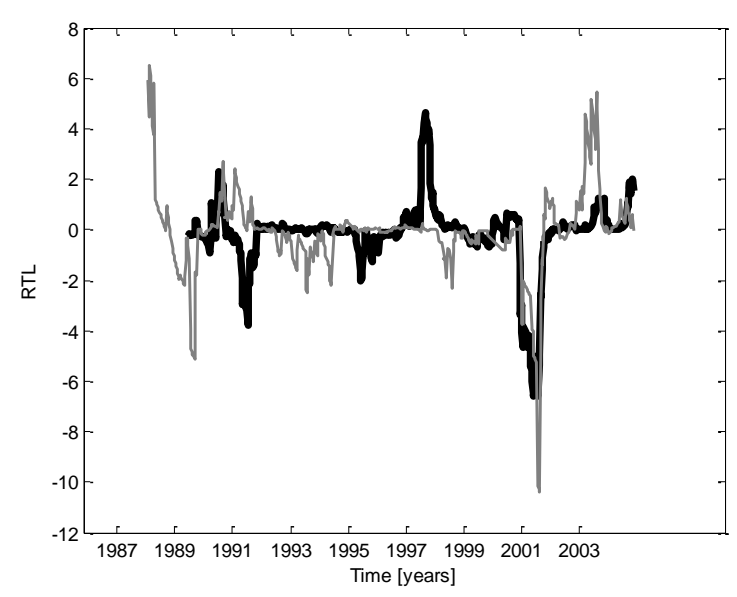

(n)

Figure 4 


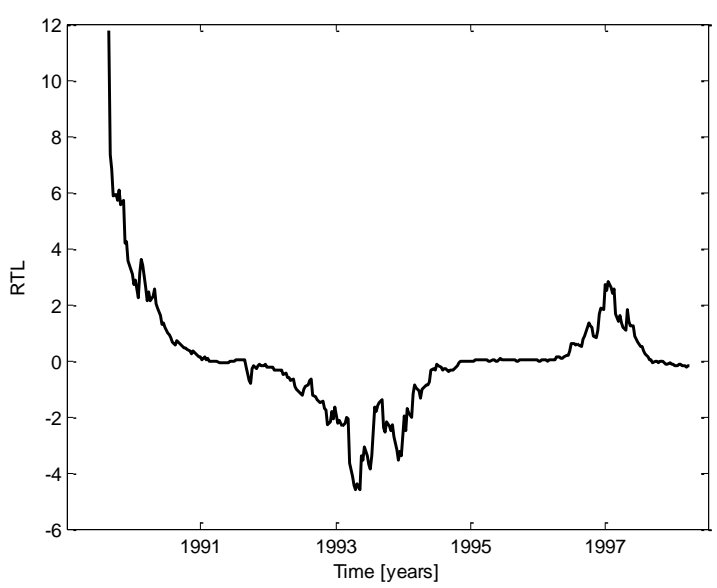

(a)

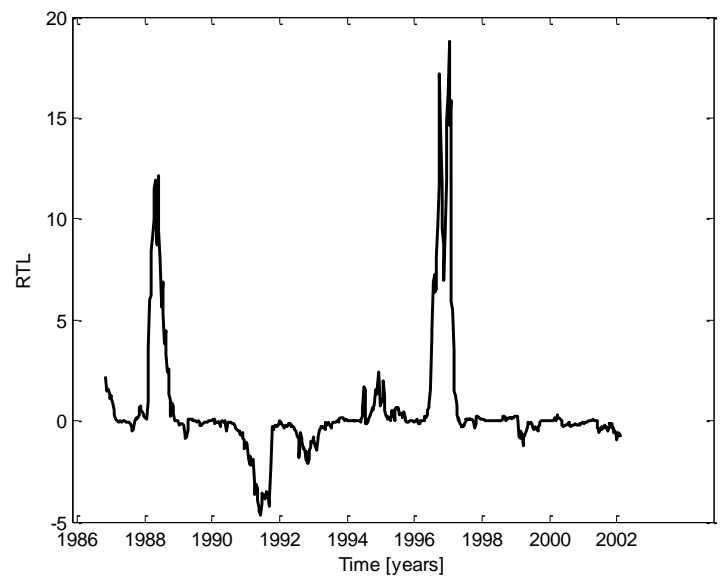

(b)

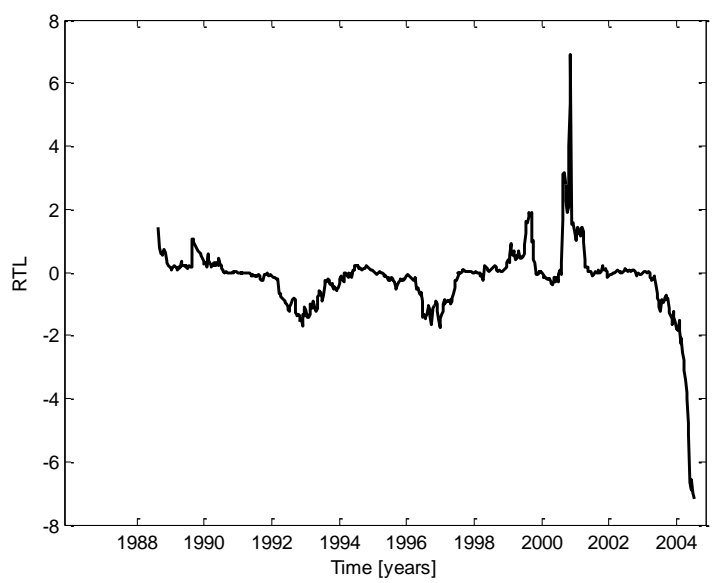

(c)

Figure5 


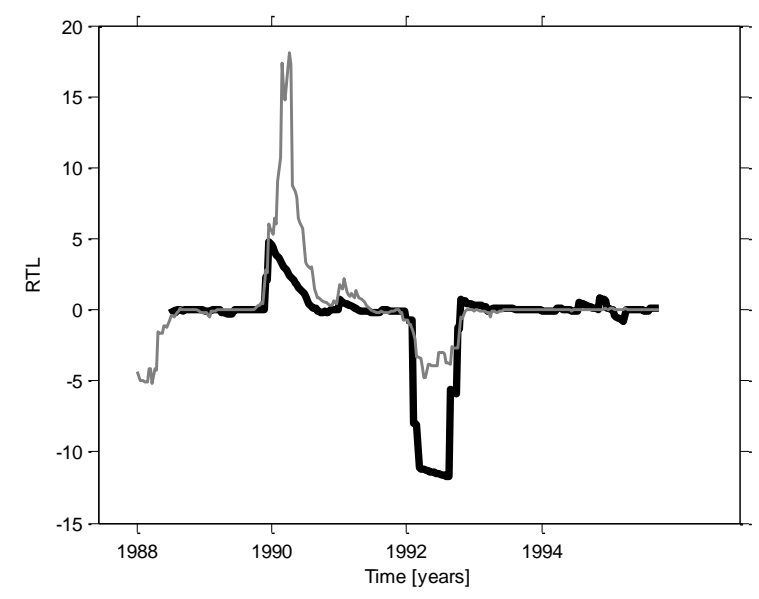

(a)

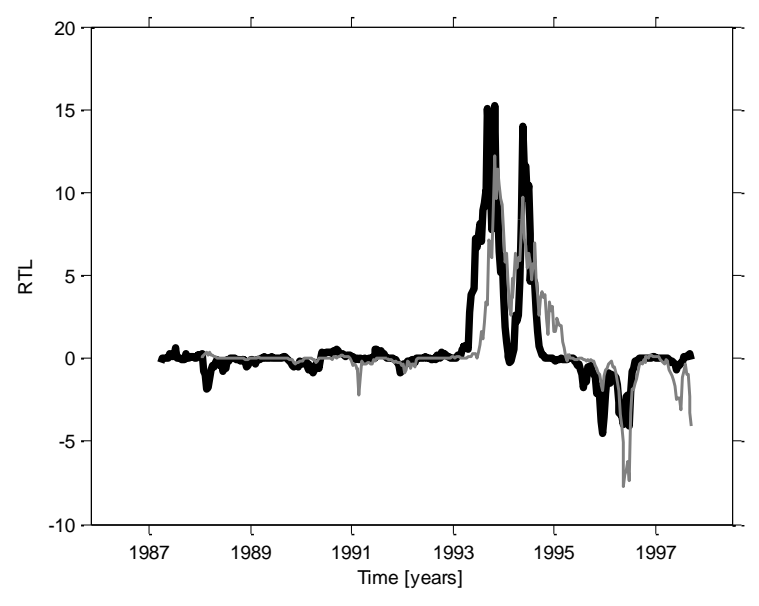

(c)

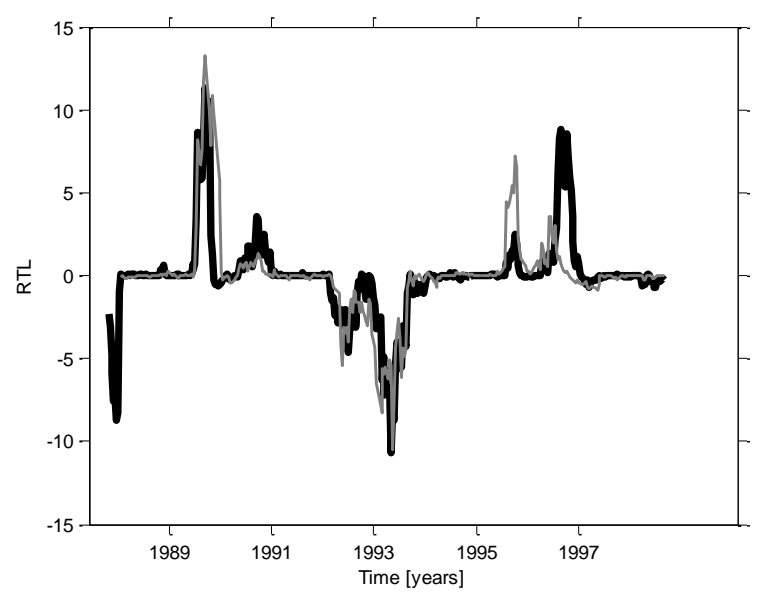

(e)

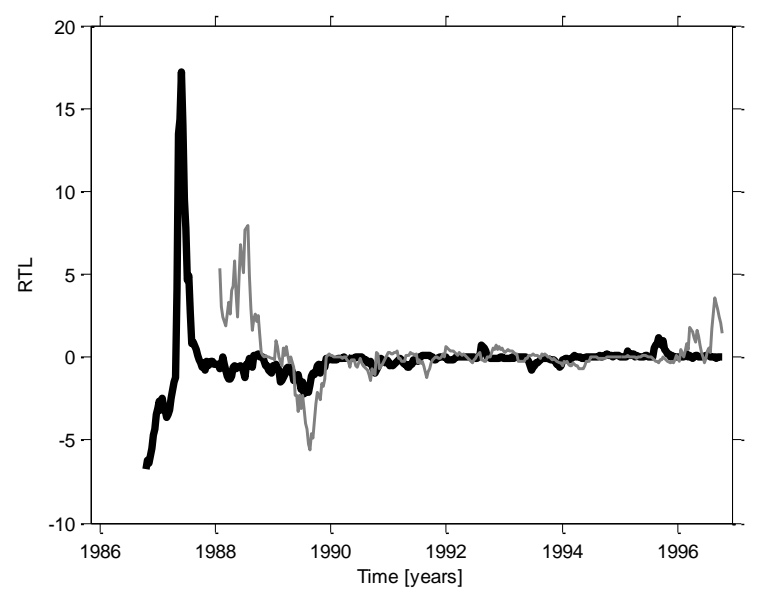

(b)

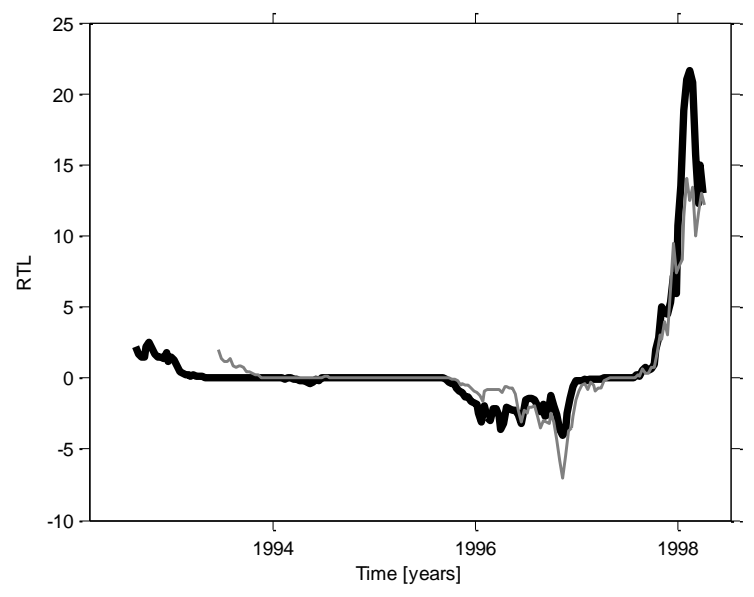

(d)

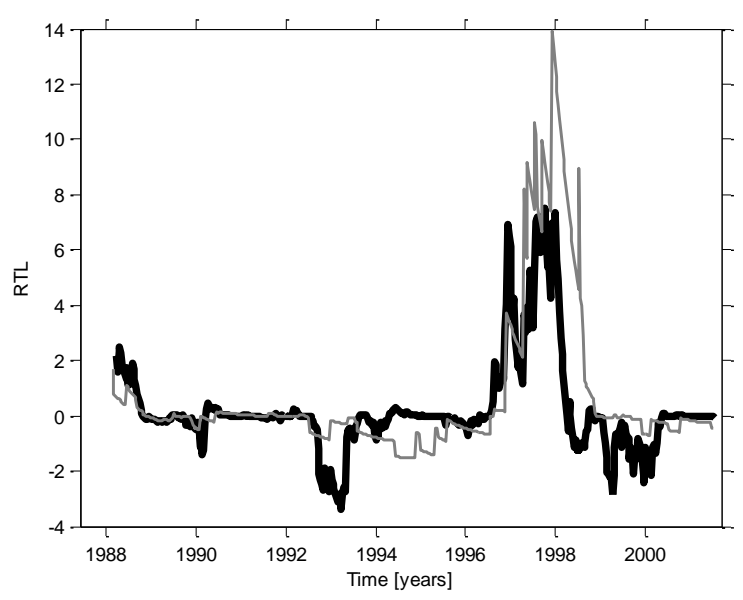

(f) 


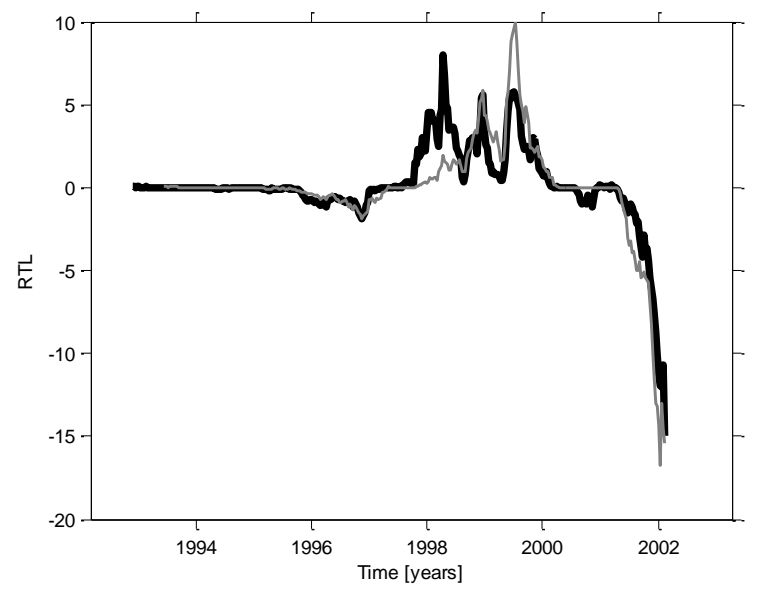

(g)

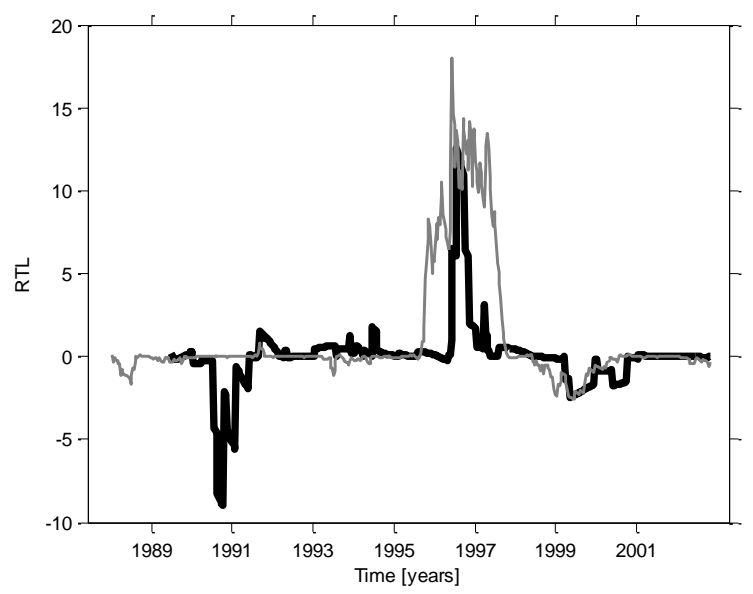

(i)

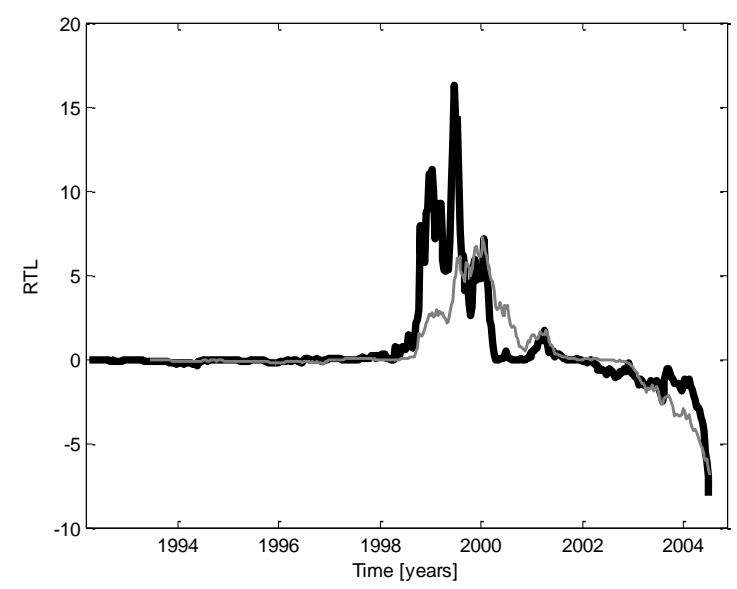

(m)

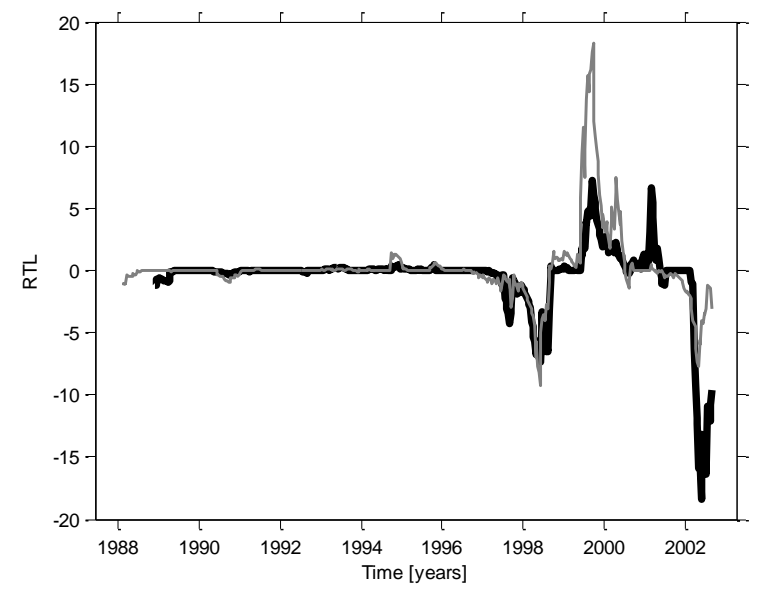

(h)

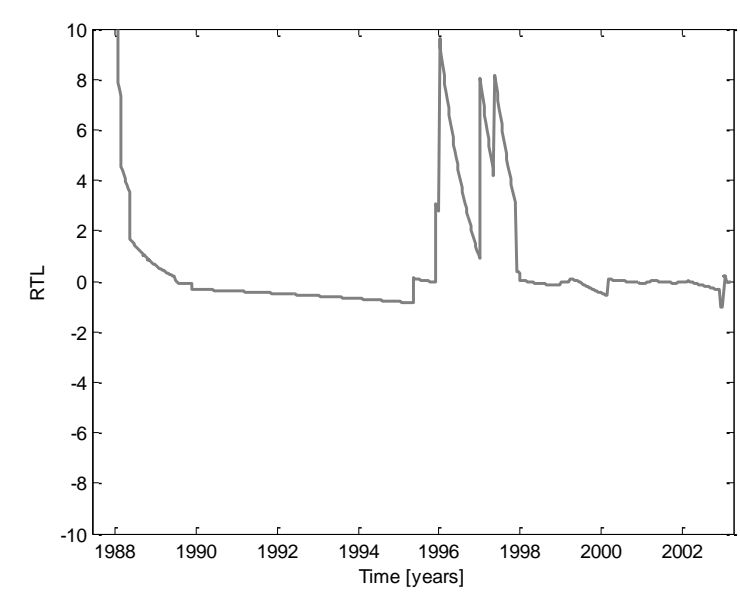

(1)

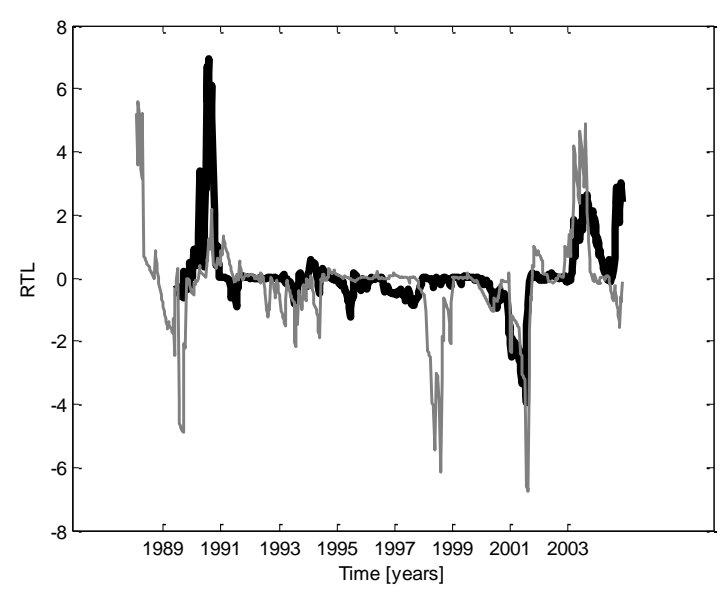

(n)

Figure 6 


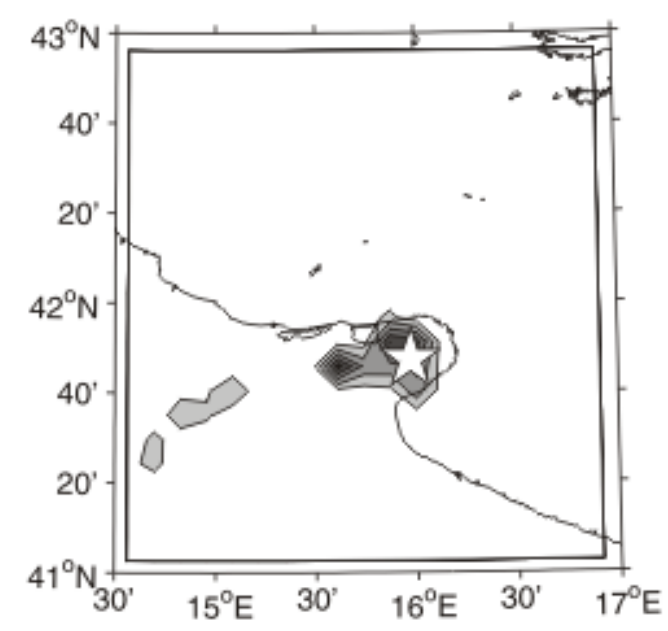

(a)

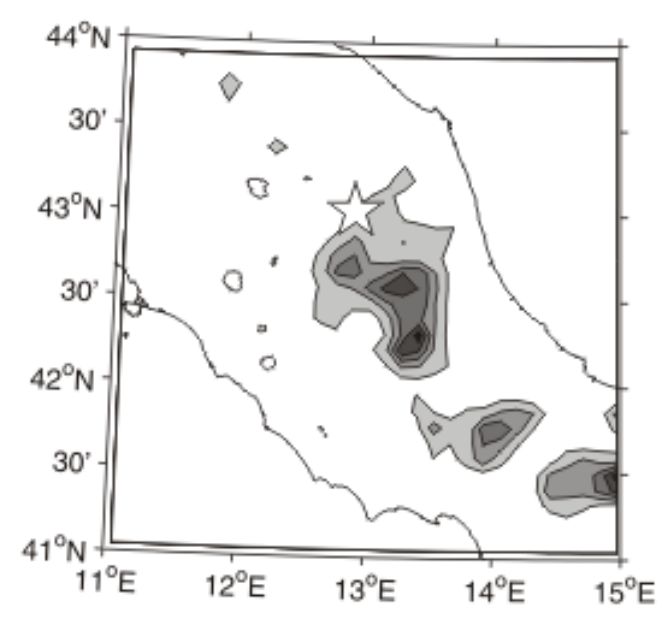

(c)

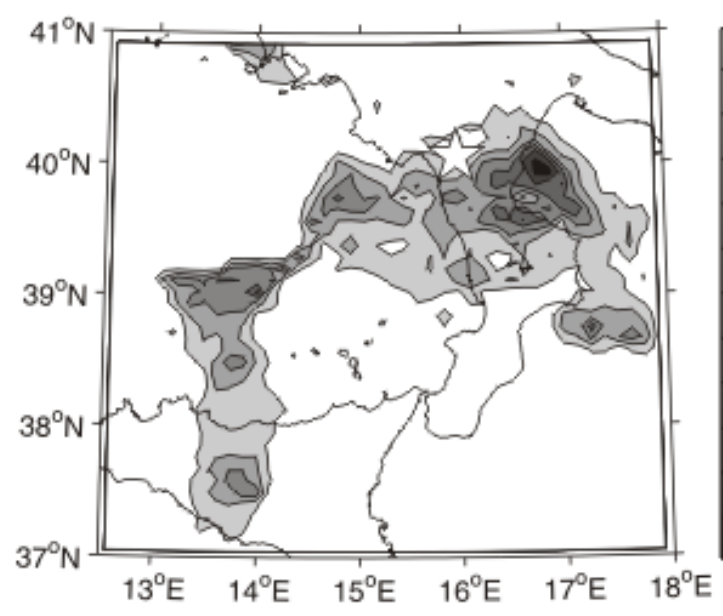

(e)

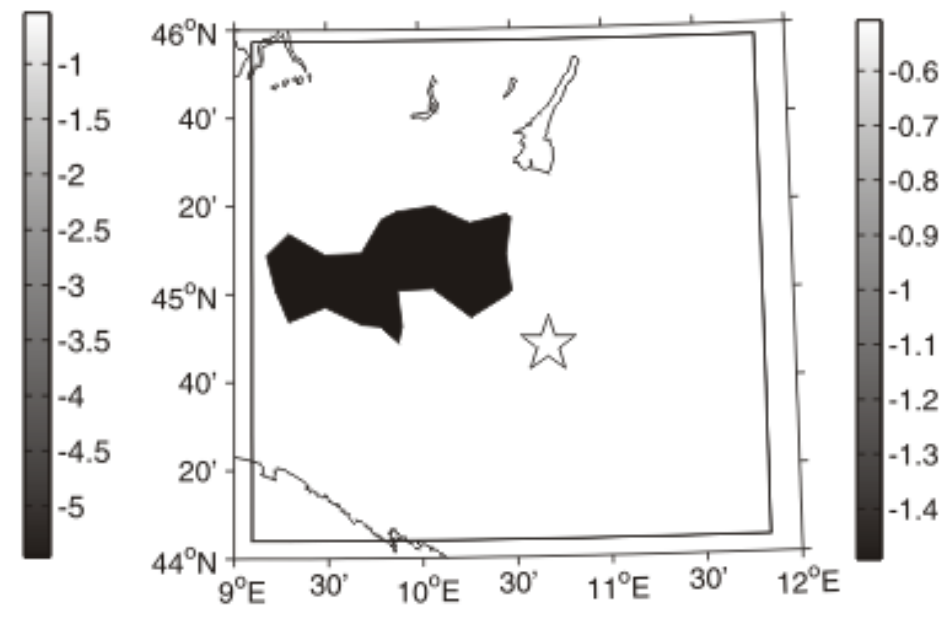

(b)

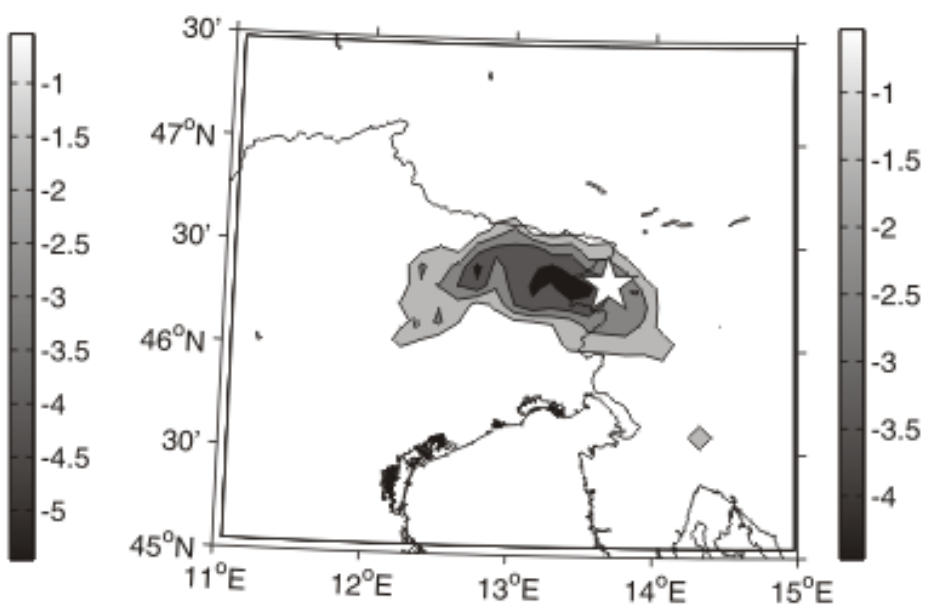

(d)

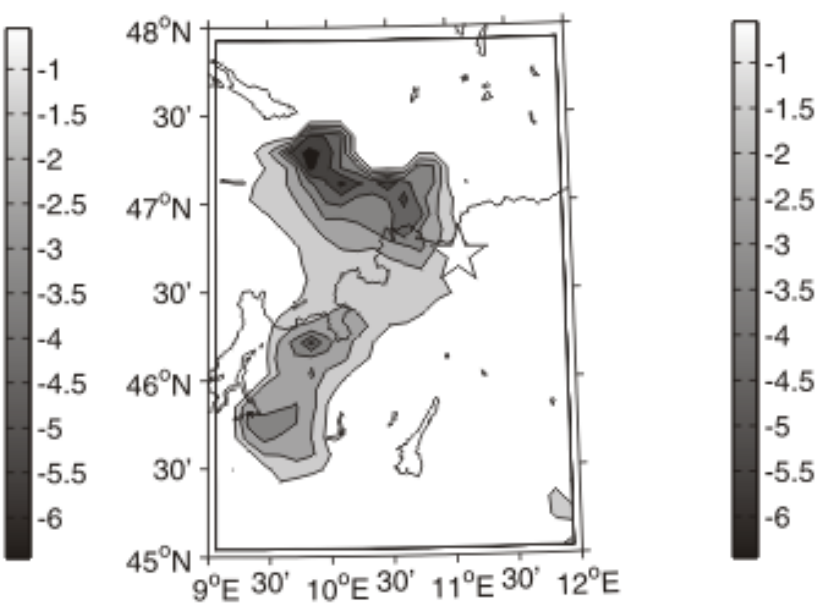

(f) 


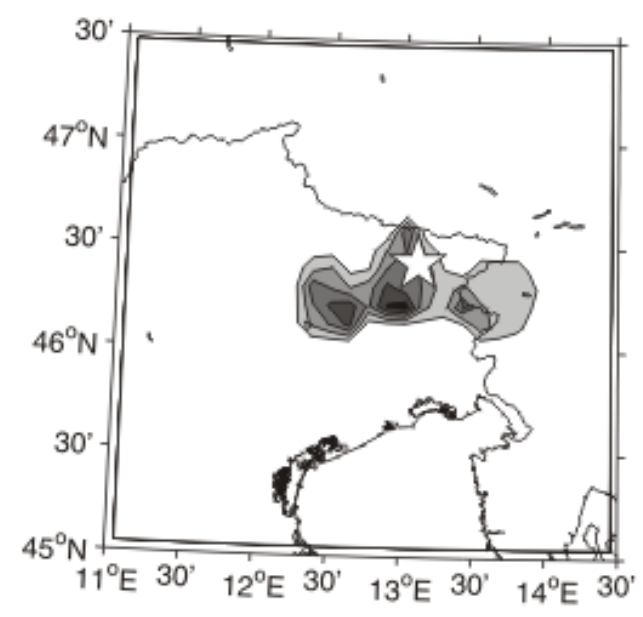

(g)

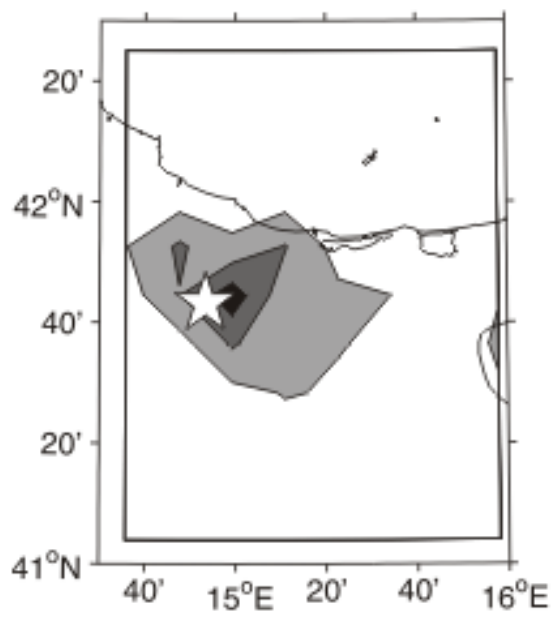

(i)

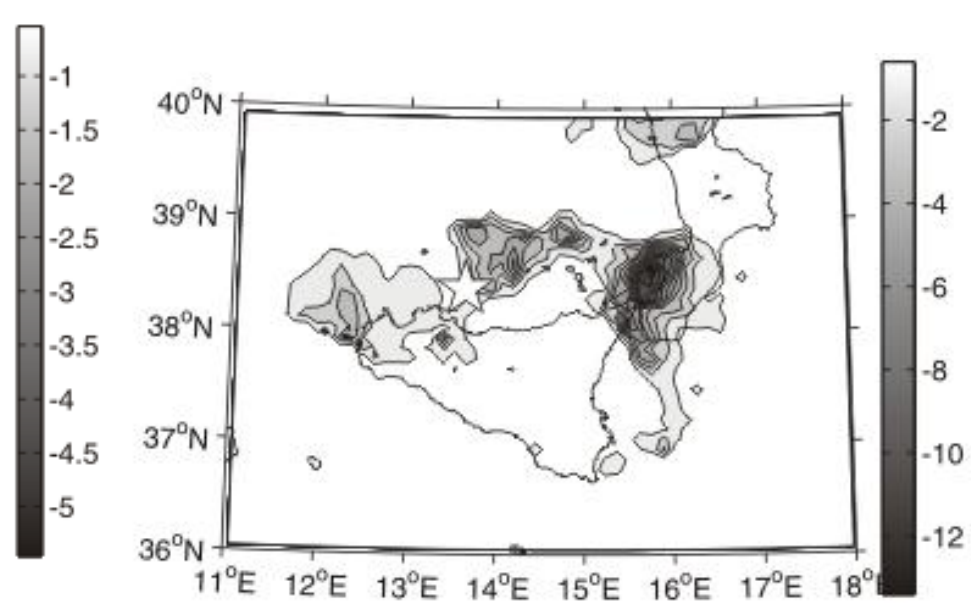

(h)
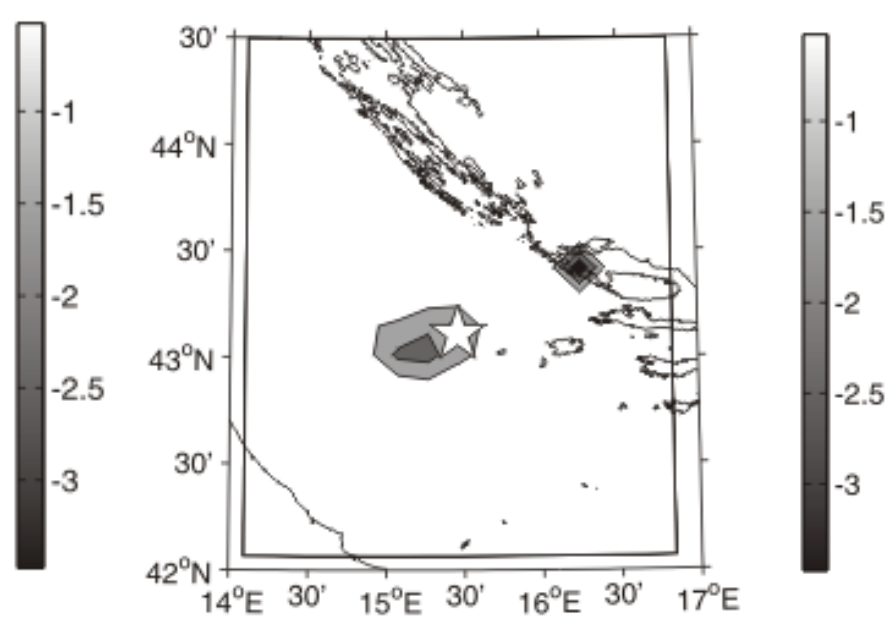

(1)

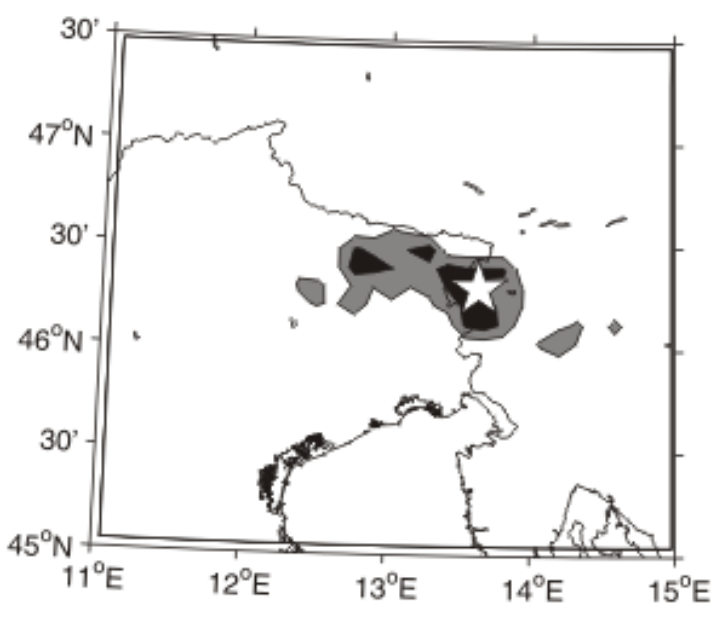

(m)
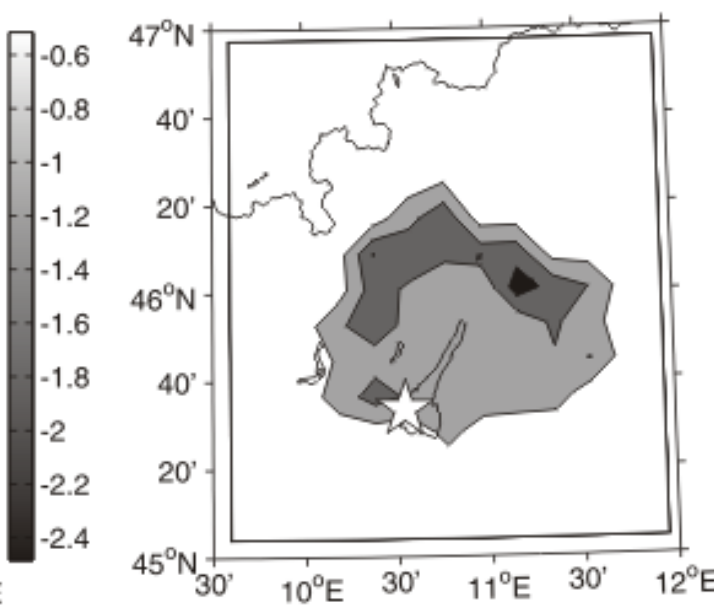

(n)

Figure 7 


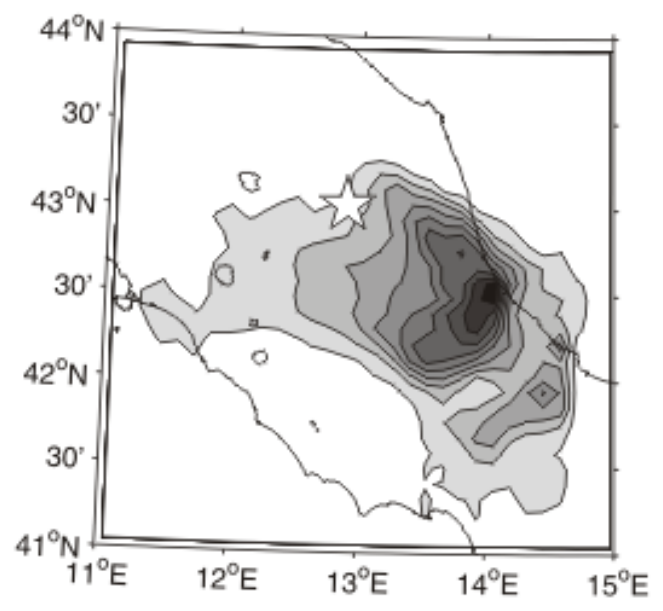

(a)
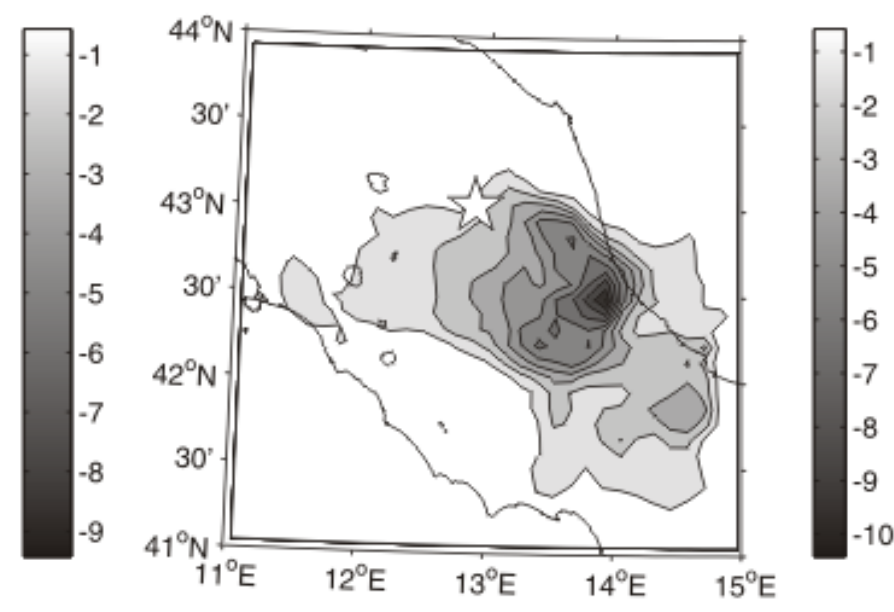

(b)

Figure 8 


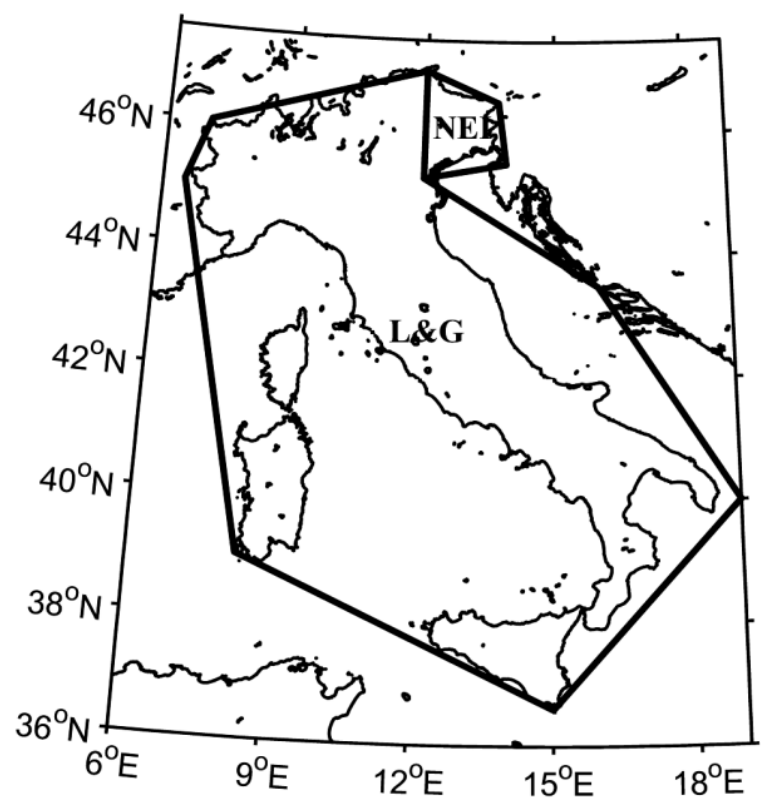

(a)

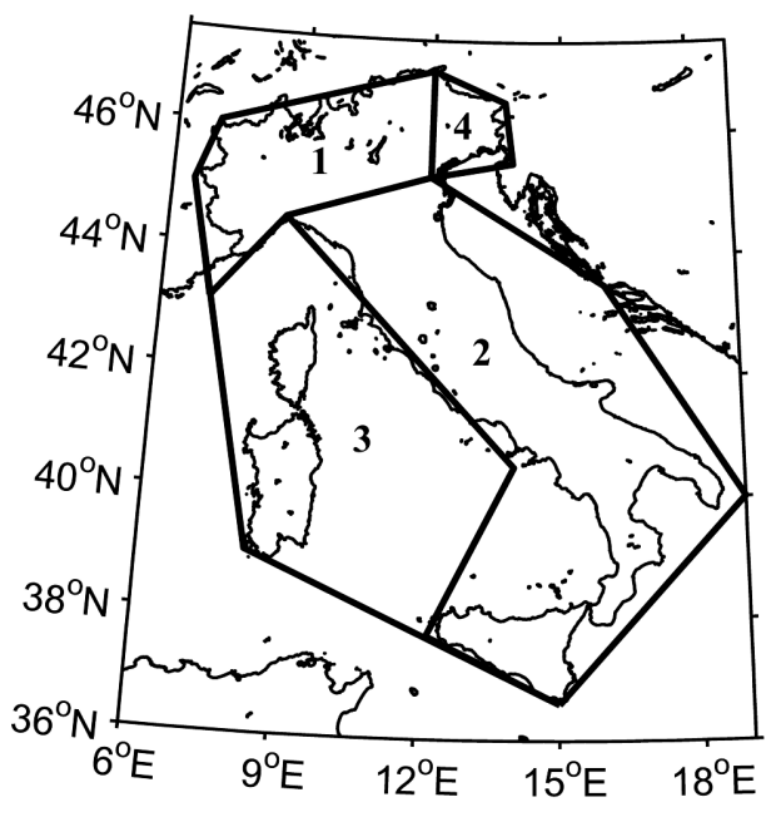

(b)

Figure 9 


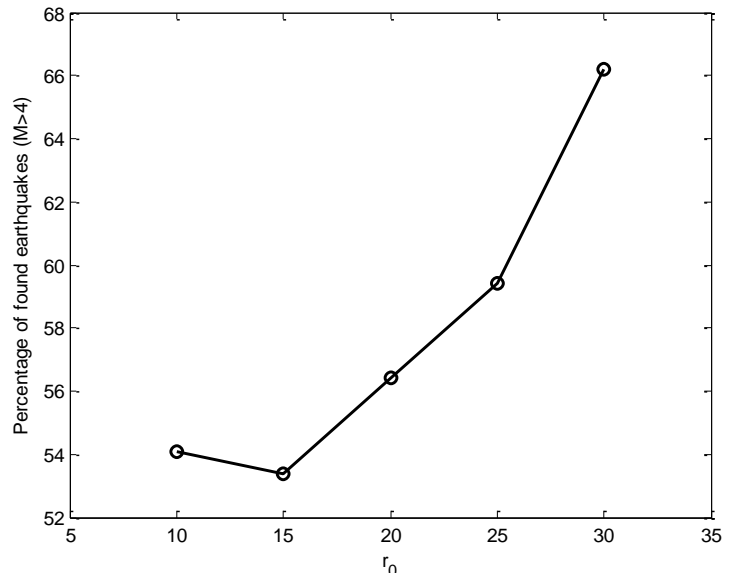

(a)

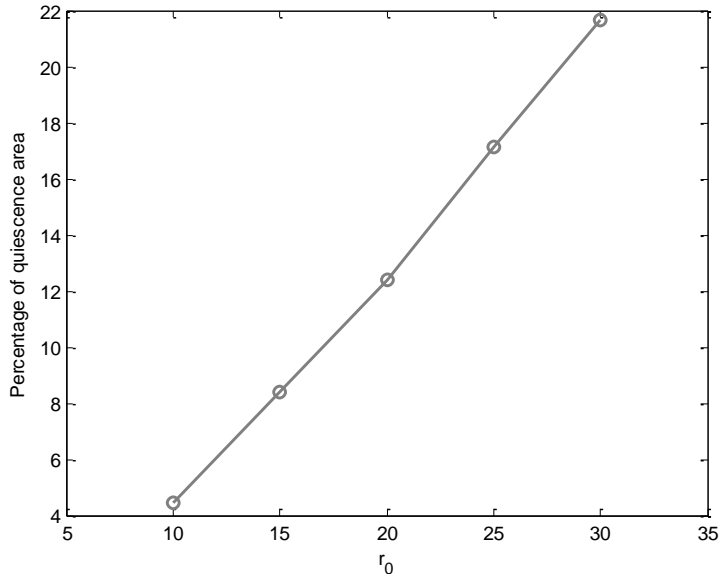

(b)

Figure 10 


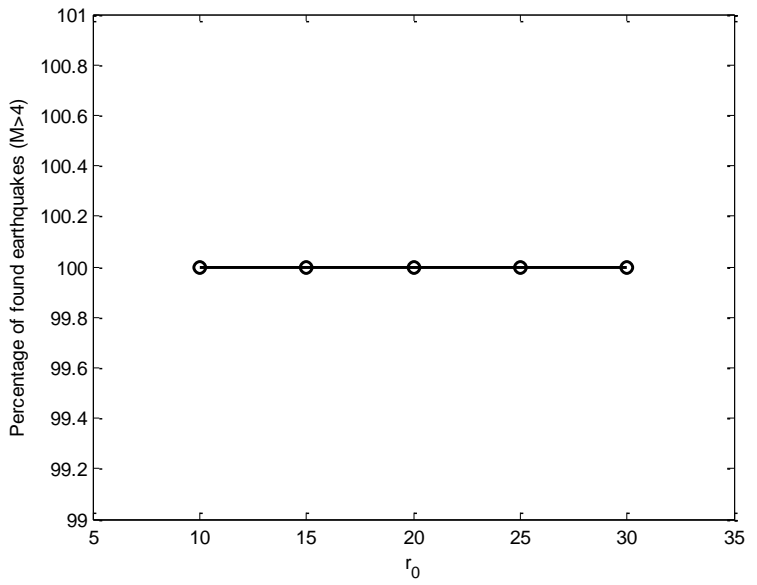

(a)

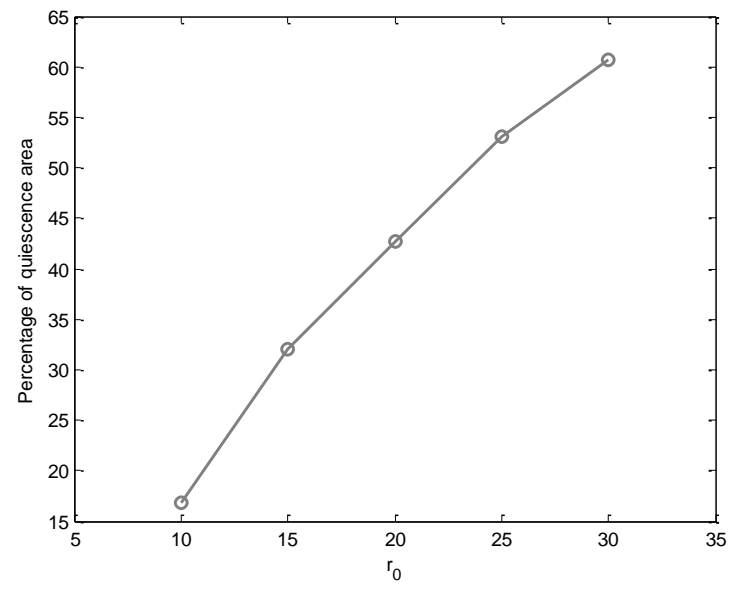

(b)

Figure 11 


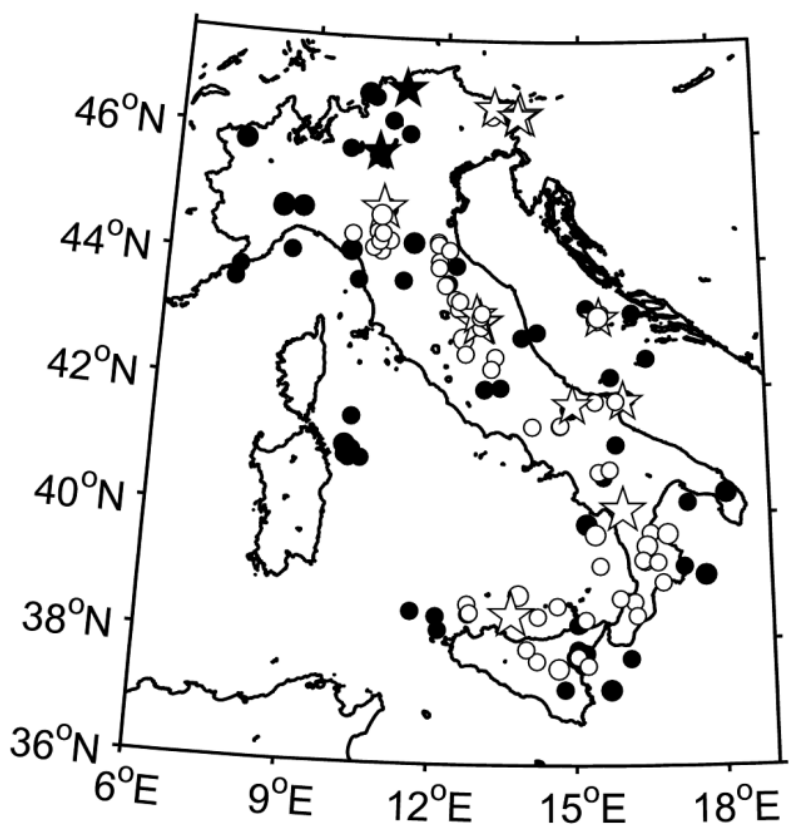

(a)

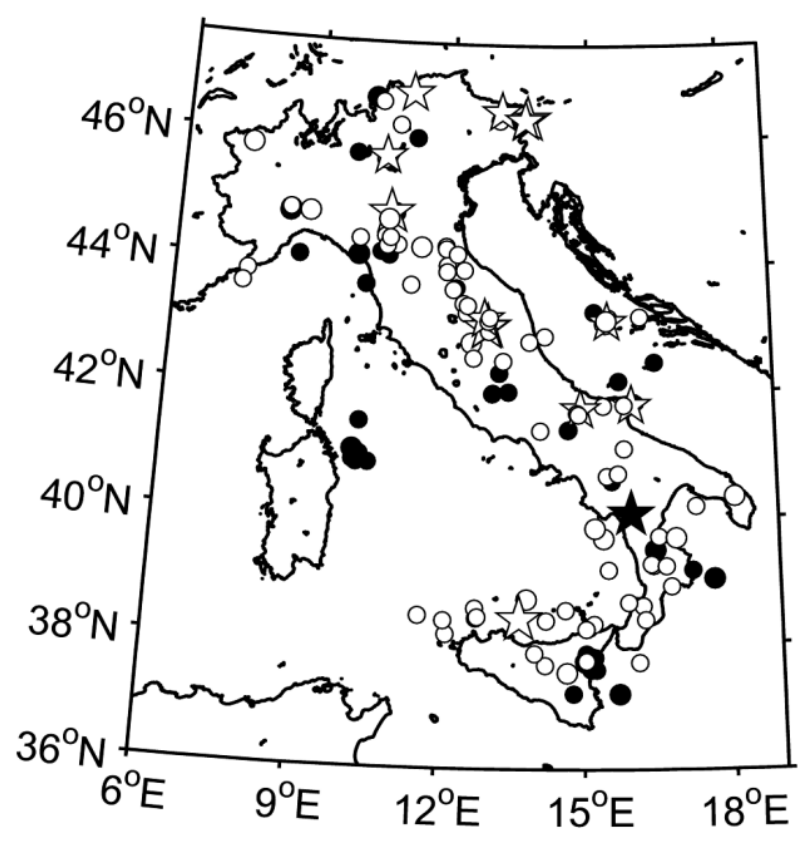

(b)

Figure 12 
Tables

\begin{tabular}{|c|c|c|c|c|c|c|c|}
\hline $\begin{array}{l}\text { Date } \\
\text { (UTC) }\end{array}$ & $\begin{array}{l}\text { Time } \\
\text { (UTC) }\end{array}$ & Zone & \begin{tabular}{|l} 
Lat \\
{$[\mathrm{deg}]$}
\end{tabular} & \begin{tabular}{|l} 
Lon \\
{$[\mathrm{deg}]$}
\end{tabular} & $\begin{array}{l}\text { Depth } \\
{[\mathrm{km}]}\end{array}$ & $\begin{array}{l}\mathrm{M}_{\mathrm{L}} \\
(\mathrm{L} \& \mathrm{G})\end{array}$ & $\begin{array}{l}\mathrm{M}_{\mathrm{D}} \\
(\mathrm{NEI})\end{array}$ \\
\hline 1994/01/05 & $13: 24: 08$ & South Tyrrhenian Sea & 38.97 & 15.41 & 307 & 5.7 & - \\
\hline 1995/09/30 & 10:14:34 & Gargano (Apulia) & 41.79 & 15.97 & 28 & 5.4 & - \\
\hline $1996 / 10 / 15$ & 09:56:00 & Reggio Emilia & 44.80 & 10.68 & 1 & 5.5 & - \\
\hline $1997 / 09 / 26$ & 00:33:13 & Umbria Marche & 43.02 & 12.89 & 4 & 5.6 & - \\
\hline $1997 / 09 / 26$ & $09: 40: 27$ & Umbria Marche & 43.01 & 12.85 & 10 & 5.8 & - \\
\hline 1997/10/06 & $23: 24: 53$ & Umbria Marche & 43.03 & 12.85 & 4 & 5.4 & - \\
\hline $1997 / 10 / 12$ & 11:08:37 & Umbria Marche & 42.91 & 12.92 & 0 & 5.1 & - \\
\hline $1997 / 10 / 14$ & $15: 23: 11$ & Umbria Marche & 42.90 & 12.90 & 7 & 5.5 & - \\
\hline $1998 / 03 / 26$ & $16: 26: 17$ & Umbria Marche & 43.15 & 12.81 & 45 & 5.4 & - \\
\hline 1998/04/03 & $07: 26: 37$ & Umbria Marche & 43.19 & 12.76 & 2 & 5.3 & - \\
\hline 1998/04/12 & $10: 55: 33$ & Kobarid & 46.32 & 13.68 & 15 & 5.6 & 5.6 \\
\hline $1998 / 05 / 18$ & 17:19:11 & South Tyrrhenian Sea & 39.06 & 15.02 & 219 & 5.4 & - \\
\hline 1998/09/09 & 11:28:00 & $\begin{array}{l}\text { Calabrian-Lucanian } \\
\text { Apennines }\end{array}$ & 40.06 & 15.95 & 29 & 5.6 & - \\
\hline 2001/07/17 & 15:06:15 & Merano & 46.70 & 11.07 & $\mathbf{0}$ & 5.3 & 5.2 \\
\hline 2002/02/14 & 03:18:03 & Sernio Mountain & 46.43 & 13.10 & 11 & 4.9 & 4.9 \\
\hline $2002 / 09 / 06$ & 01:21:29 & Palermo & 38.38 & 13.65 & 27 & 5.6 & - \\
\hline $2002 / 10 / 31$ & 10:32:59 & Molise & 41.72 & 14.89 & 25 & 5.4 & - \\
\hline $2002 / 11 / 01$ & 15:09:02 & Molise & 41.74 & 14.84 & 21 & 5.3 & - \\
\hline $2003 / 03 / 29$ & 17:42:16 & Adriatic Sea & 43.11 & 15.46 & 10 & 5.4 & - \\
\hline $2004 / 05 / 05$ & $13: 39: 43$ & Aeolian Islands & 38.51 & 14.88 & 240 & 5.3 & - \\
\hline $2004 / 07 / 12$ & 13:04:07 & Kobarid & 46.30 & 13.63 & 5 & 5.2 & 5.1 \\
\hline $2004 / 11 / 24$ & 22:59:39 & Garda Lake & 45.56 & 10.57 & 5 & 5.2 & 4.9 \\
\hline
\end{tabular}

Table 1 


\begin{tabular}{|l|l|l|l|l|}
\hline Date & Zone & Catalogue & Magnitude & $\mathrm{M}_{\mathrm{c}}$ \\
\hline $1995 / 09 / 30$ & Gargano (Apulia) & L\&G & $\mathrm{M}_{\mathrm{L}}$ & 2.5 \\
\hline $1996 / 10 / 15$ & Reggio Emilia & L\&G & $\mathrm{M}_{\mathrm{L}}$ & 2.0 \\
\hline $1997 / 09 / 26$ & Umbria Marche & L\&G & $\mathrm{M}_{\mathrm{L}}$ & 2.0 \\
\hline $1998 / 04 / 12$ & Kobarid & NEI & $\mathrm{M}_{\mathrm{D}}$ & 2.2 \\
\hline $1998 / 09 / 09$ & Calabrian-Lucanian Apennines & L\&G & $\mathrm{M}_{\mathrm{L}}$ & 2.2 \\
\hline $2001 / 07 / 17$ & Merano & L\&G & $\mathrm{M}_{\mathrm{L}}$ & 2.1 \\
\hline $2002 / 02 / 14$ & Sernio Mountain & NEI & $\mathrm{M}_{\mathrm{D}}$ & 2.4 \\
\hline $2002 / 09 / 06$ & Palermo & L\&G & $\mathrm{M}_{\mathrm{L}}$ & 2.3 \\
\hline $2002 / 10 / 31$ & Molise & L\&G & $\mathrm{M}_{\mathrm{L}}$ & 2.3 \\
\hline $2003 / 03 / 29$ & Adriatic Sea & NEI & $\mathrm{M}_{\mathrm{L}}$ & 2.7 \\
\hline $2004 / 07 / 12$ & Kobarid & L\&G & $\mathrm{M}_{\mathrm{L}}$ & 2.3 \\
\hline $2004 / 11 / 24$ & Garda Lake & & 2.2 \\
\hline
\end{tabular}

Table 2 


\begin{tabular}{|l|l|l|l|l|}
\hline Zone & $\mathrm{t}_{0}$ [years] & $\mathrm{p}\left(\mathrm{t}_{0}\right)$ & $\mathrm{r}_{0}[\mathrm{~km}]$ & $\mathrm{p}\left(\mathrm{r}_{0}\right)$ \\
\hline Gargano (Apulia) & 1.1 & $47 \%$ & 15 & $76 \%$ \\
\hline Reggio Emilia & 0.4 & $92 \%$ & 55 & $43 \%$ \\
\hline Umbria Marche & 0.6 & $93 \%$ & 35 & $100 \%$ \\
\hline Kobarid 1998 & 0.6 & $100 \%$ & 60 & $98 \%$ \\
\hline Calabrian-Lucanian Apennines & 0.9 & $55 \%$ & 45 & $93 \%$ \\
\hline Merano & 1.1 & $53 \%$ & 65 & $92 \%$ \\
\hline Sernio Mountain & 0.6 & $100 \%$ & 25 & $100 \%$ \\
\hline Palermo & 1.4 & $45 \%$ & 30 & $99 \%$ \\
\hline Molise & 1.4 & $77 \%$ & 15 & $86 \%$ \\
\hline Adriatic Sea & 1.0 & $72 \%$ & 25 & $52 \%$ \\
\hline Kobarid 2004 & 0.4 & $100 \%$ & 40 & $92 \%$ \\
\hline Garda Lake & 1.7 & $22 \%$ & 55 & $67 \%$ \\
\hline
\end{tabular}

Table 3 


\begin{tabular}{|l|l|l|l|}
\hline Zone & $\mathrm{M}_{\mathrm{c}}$ & $\mathrm{M}_{\min }$ & $\mathrm{M}_{\max }$ \\
\hline Gargano (Apulia) & 2.5 & 0 & 2.8 \\
\hline Reggio Emilia & 2.0 & - & - \\
\hline Umbria Marche & 2.0 & 0 & 3.5 \\
\hline Kobarid & 2.2 & 0 & 3.3 \\
\hline Calabrian-Lucanian Apennines & 2.2 & 0 & 3.5 \\
\hline Merano & 2.1 & 1.5 & 3.1 \\
\hline Sernio Mountain & 2.4 & 0 & 3.1 \\
\hline Palermo & 2.3 & 0 & 3.1 \\
\hline Molise & 2.3 & 0 & 2.8 \\
\hline Adriatic Sea & 2.7 & 0 & 3.1 \\
\hline Kobarid & 2.3 & 0 & 3.2 \\
\hline Garda Lake & 2.2 & 0 & 3.2 \\
\hline
\end{tabular}

Table 4 


\begin{tabular}{|l|l|l|l|l|}
\hline Zone & $\begin{array}{l}\text { Quiescence } \\
\text { Duration } \\
{[\text { years }]}\end{array}$ & $\begin{array}{l}\text { Quiescence } \\
\text { shift } \\
{[\text { years }]}\end{array}$ & $\begin{array}{l}\text { Activation } \\
\text { Duration } \\
{[\text { years }]}\end{array}$ & $\begin{array}{l}\text { Activation } \\
\text { Shift } \\
\text { [years] }\end{array}$ \\
\hline Gargano (Apulia) & 1.1 & 2.9 & - & - \\
\hline Reggio Emilia & - & - & - & - \\
\hline Umbria Marche & 2.0 & 0.3 & - & - \\
\hline Kobarid 1998 & 1.6 & 1.0 & 0.7 & 0 \\
\hline Calabrian-Lucanian Apennines & 0.6 & 0 & - & - \\
\hline Merano & 2.2 & 1.2 & - & - \\
\hline Sernio Mountain & 0.6 & 0 & - & - \\
\hline Palermo & 1.4 & 0 & - & - \\
\hline Molise & 1.4 & 1.8 & - & - \\
\hline Adriatic Sea & 1.5 & 0.03 & 0.03 & 0 \\
\hline Kobarid 2004 & 3.0 & 0 & - & - \\
\hline Garda Lake & 1.2 & 2.8 & 0.5 & 0 \\
\hline
\end{tabular}

Table 5 


\begin{tabular}{|c|c|c|c|c|c|c|c|c|}
\hline \multirow[b]{2}{*}{ Zone } & \multirow[b]{2}{*}{$\mathrm{M}_{\mathrm{c}}$} & \multirow[b]{2}{*}{$\begin{array}{l}\text { Analysis } \\
\text { time interval } \\
\text { [year/month/day] }\end{array}$} & \multicolumn{2}{|c|}{ Cheng and $\mathrm{Wu}$} & \multicolumn{2}{|c|}{ Threshold on $r_{0}$} & \multicolumn{2}{|c|}{ Minimum radius } \\
\hline & & & $\begin{array}{l}\mathrm{r}_{0} \\
{[\mathrm{~km}]}\end{array}$ & $\begin{array}{l}\text { Quiescence } \\
\text { anomaly } \\
\text { dimension }\end{array}$ & $\begin{array}{l}\mathrm{r}_{0} \\
{[\mathrm{~km}]}\end{array}$ & $\begin{array}{l}\text { Quiescence } \\
\text { anomaly } \\
\text { dimension }\end{array}$ & $\begin{array}{l}\mathrm{r}_{0} \\
{[\mathrm{~km}]}\end{array}$ & $\begin{array}{l}\text { Quiescence } \\
\text { anomaly } \\
\text { dimension }\end{array}$ \\
\hline $\begin{array}{l}\text { Gargano } \\
\text { (Apulia) }\end{array}$ & 2.5 & $\begin{array}{l}1991 / 10 / 25- \\
1992 / 10 / 26\end{array}$ & 15 & $\sim 100 \mathrm{~km}$ & 15 & $\sim 100 \mathrm{~km}$ & 10 & $\sim 50 \mathrm{~km}$ \\
\hline $\begin{array}{l}\text { Reggio } \\
\text { Emilia }\end{array}$ & 2.1 & $\begin{array}{l}\text { 1995/10/16- } \\
1996 / 10 / 15\end{array}$ & 55 & - & 30 & - & - & - \\
\hline $\begin{array}{l}\text { Umbria } \\
\text { Marche }\end{array}$ & 2.2 & $\begin{array}{l}1995 / 07 / 02- \\
1996 / 07 / 01\end{array}$ & 35 & $\sim 300 \mathrm{~km}$ & 30 & $\sim 300 \mathrm{~km}$ & 10 & $\sim 150 \mathrm{~km}$ \\
\hline $\begin{array}{l}\text { Kobarid } \\
1998\end{array}$ & 2.2 & $\begin{array}{l}\text { 1995/12/01- } \\
1996 / 11 / 30\end{array}$ & 60 & $\sim 350 \mathrm{~km}$ & 30 & $\sim 250 \mathrm{~km}$ & 10 & $\sim 150 \mathrm{~km}$ \\
\hline $\begin{array}{l}\text { Calabrian- } \\
\text { Lucanian } \\
\text { Apennines }\end{array}$ & 2.4 & $\begin{array}{l}1997 / 09 / 10- \\
1998 / 09 / 09\end{array}$ & 45 & $\sim 500 \mathrm{~km}$ & 30 & $\sim 450 \mathrm{~km}$ & 30 & $\sim 450 \mathrm{~km}$ \\
\hline Merano & 2.1 & $\begin{array}{l}\text { 1999/01/28- } \\
2000 / 01 / 27\end{array}$ & 65 & $\sim 800 \mathrm{~km}$ & 30 & $\sim 200 \mathrm{~km}$ & 30 & $\sim 200 \mathrm{~km}$ \\
\hline $\begin{array}{l}\text { Sernio } \\
\text { Mountain }\end{array}$ & 2.4 & $\begin{array}{l}\text { 2001/02/14- } \\
2002 / 02 / 13\end{array}$ & 25 & $\sim 200 \mathrm{~km}$ & 25 & $\sim 200 \mathrm{~km}$ & 10 & $\sim 150 \mathrm{~km}$ \\
\hline Palermo & 2.3 & $\begin{array}{l}\text { 2001/09/06- } \\
2002 / 09 / 05\end{array}$ & 30 & $\sim 500 \mathrm{~km}$ & 30 & $\sim 500 \mathrm{~km}$ & 10 & $\sim 100 \mathrm{~km}$ \\
\hline Molise & 2.3 & $\begin{array}{l}1999 / 10 / 29- \\
2000 / 10 / 28\end{array}$ & 15 & $\sim 100 \mathrm{~km}$ & 15 & $\sim 100 \mathrm{~km}$ & 15 & $\sim 100 \mathrm{~km}$ \\
\hline Adriatic Sea & 2.7 & $\begin{array}{l}\text { 2002/03/17- } \\
2003 / 03 / 16\end{array}$ & 25 & $\sim 150 \mathrm{~km}$ & 25 & $\sim 150 \mathrm{~km}$ & 20 & $\sim 50 \mathrm{~km}$ \\
\hline $\begin{array}{l}\text { Kobarid } \\
2004\end{array}$ & 2.4 & $\begin{array}{l}\text { 2003/07/12- } \\
2004 / 07 / 11\end{array}$ & 40 & $\sim 350 \mathrm{~km}$ & 30 & $\sim 300 \mathrm{~km}$ & 10 & $\sim 100 \mathrm{~km}$ \\
\hline Garda Lake & 2.2 & $\begin{array}{l}2000 / 12 / 28- \\
2001 / 12 / 27\end{array}$ & 55 & $\sim 600 \mathrm{~km}$ & 30 & $\sim 300 \mathrm{~km}$ & 30 & $\sim 300 \mathrm{~km}$ \\
\hline
\end{tabular}

Table 6 


\begin{tabular}{|c|c|c|c|c|c|c|}
\hline $\begin{array}{c}\text { Zone } \\
\text { number }\end{array}$ & $\begin{array}{c}\mathrm{r}_{0} \\
{[\mathrm{~km}]}\end{array}$ & $\begin{array}{c}\text { Alarm } \\
\text { area }\end{array}$ & $\begin{array}{c}\text { True } \\
\text { alarm }\end{array}$ & $\begin{array}{c}\text { False } \\
\text { alarm }\end{array}$ & $\begin{array}{c}\text { Found earth. } \\
\mathrm{M}_{\mathrm{L}}>4\end{array}$ & $\begin{array}{c}\text { Found earth. } \\
\mathrm{M}_{\mathrm{L}}>5\end{array}$ \\
\hline 1 & 30 & $18.4 \%$ & $2.9 \%$ & $15.5 \%$ & $66.7 \%$ & $100 \%$ \\
\hline 2 & 10 & $8.7 \%$ & $1.2 \%$ & $7.5 \%$ & $66.0 \%$ & $100 \%$ \\
\hline 4 & 10 & $16.9 \%$ & $1.9 \%$ & $14.9 \%$ & $100.0 \%$ & $100 \%$ \\
\hline
\end{tabular}

Table 7 